\title{
Regulatory Considerations for Approval of Generic Inhalation Drug Products in the US, EU, Brazil, China, and India
}

\author{
Sau L. Lee, ${ }^{1}$ Bhawana Saluja, ${ }^{1}$ Alfredo García-Arieta, ${ }^{2}$ Gustavo Mendes Lima Santos, ${ }^{3}$ Ying Li, ${ }^{4}$ Sarah Lu, ${ }^{5}$ \\ Shuguang Hou, ${ }^{6}$ Juliet Rebello, ${ }^{7}$ Abhijit Vaidya, ${ }^{7}{ }^{\text {Jaideep Gogtay, }}{ }^{7}$ \\ Shrinivas Purandare, ${ }^{8}$ and Svetlana Lyapustina $9,10,11$
}

Received 15 January 2015; accepted 9 May 2015; published online 23 May 2015

\begin{abstract}
This article describes regulatory approaches for approval of "generic" orally inhaled drug products (OIDPs) in the United States, European Union, Brazil, China and India. While registration of a generic OIDP in any given market may require some documentation of the formulation and device similarity to the "original" product as well as comparative testing of in vitro characteristics and in vivo performance, the specific documentation approaches, tests and acceptance criteria vary by the country. This divergence is due to several factors, including unique cultural, historical, legal and economic circumstances of each region; the diverse healthcare and regulatory systems; the different definitions of key terms such as "generic" and "reference" drug; the acknowledged absence of in vitro in vivo correlations for OIDPs; and the scientific and statistical issues related to OIDP testing (such as how best to account for the batch-to-batch variability of the Reference product, whether to use average bioequivalence or population bioequivalence in the statistical analysis of results, whether to use healthy volunteers or patients for pharmacokinetic studies, and which pharmacodynamic or clinical end-points should be used). As a result of this discrepancy, there are ample opportunities for the regulatory and scientific communities around the world to collaborate in developing more consistent, better aligned, science-based approaches. Moving in that direction will require both further research and further open discussion of the pros and cons of various approaches.
\end{abstract}

KEYWORDS: bioequivalence; emerging markets; generics; pMDIs and DPIs; regulatory requirements.

This article reflects the views of the authors and should not be construed to represent the positions or policies of the organizations with which the authors are affiliated.

${ }^{1}$ Center for Drug Evaluation and Research, US Food and Drug Administration, Silver Spring, MD, USA.

${ }^{2}$ Pharmacokinetic and Generics Service, Spanish Agency for Medicines and Health Care Products, Madrid, Spain.

${ }^{3}$ Coordination of Therapeutic EquivalenceHealth Surveillance and Regulation, General Office of Medicines, Brazilian Health Surveillance Agency (Anvisa), Brasília, Brazil.

${ }^{4}$ Respiratory Product Development, Merck, Rahway, NJ, USA.

${ }^{5}$ Regulatory Affairs, Teva, Beijing, China.

${ }^{6}$ Sichuan Purity Pharmaceutical Technology Co. Ltd, Chengdu, China.

${ }^{7}$ Clinical Research Division, Cipla, Vikhroli, India.

${ }^{8}$ Regulatory Affairs, Cipla, Vikhroli, India.

${ }^{9}$ Pharmaceutical Practice Group, DBR, Washington, DC, USA.

${ }^{10}$ Drinker Biddle \& Reath LLP, 1500 K Street NW, Washington, DC 20005-1209, USA.

${ }^{11}$ To whom correspondence should be addressed. (e-mail: svetlana.lyapustina@dbr.com)

ABBREVIATIONS: ANDA, Abbreviated new drug applicaiton; ANVISA, Agência Nacional de Vigilância Sanitária (in Brazil); API, Active pharmaceutical ingredient; APSD, Aerodynamic particle size distribution; AUC, Area under the curve; BA, Bioavailability; BDP, Beclomethasone dipropionate; $\mathrm{BE}$, Bioequivalence; $\mathrm{C}_{\max }$, Maximum plasma concentration of the drug observed in a PK studyl; CCD, Center for Certification of Drugs (in China); CDSCO, Central Drugs Standard Control Organization (in India); CFC, Chlorofluorocarbon; CFDA, China Food and Drug Administration; CFR, Code of Federal Regulations (in the US); CDE, Center for Drug Evaluation (in China); CDER, Center for Drug Evaluation and Research (in US FDA); CE, Clinical endpoint; CHMP, Committee for Human Medicinal Products (in the European Union); CMDE, Center for Medical Device Evaluation (in China); COPD, Chronic obstructive pulmonary disease; CPC, Chinese Pharmacopoeia Commission; CRO, Contract Research Organization; DCGI, Drugs Controller General of India; DPI, Dry powder inhaler; ED, Emitted dose (mass); EMA, European Medicines Agency; EU, European Union; FDA, Food and Drug Administration (in the United States); $\mathrm{FEV}_{1}$, Forced expiratory volume in 1 second; FP, Fluticasone propionate; GI, Gastrointestinal; HFA, Hydrofluoroalkane; HPA, Hypothalamic-pituitary-adrenal; ICH, International Conference on Harmonisation of Technical Requirements for Registration of pharmaceuticals for human use; ICS, Inhaled corticosteroid; IPAC-RS, International Pharmaceutical Aerosol Consortium on Regulation and Science; ISM, Impactor sized mass; IVIVC, In vitro in vivo correlation; IVIVR, In vitro in vivo relationship; LABA, Long 


\section{INTRODUCTION}

Asthma, chronic obstructive pulmonary disease (COPD) and other respiratory illnesses exert a terrible toll on the health of the nations. Globally, 300 million people suffer from asthma [1] and 65 million from moderate to severe COPD [2]. In the US, over $8 \%$ of all adults and over $9 \%$ of all children have asthma [3], and COPD is the third leading cause of mortality after cancer and heart disease [4]. In some of the EU countries, up to $7 \%$ of the population reported being diagnosed with asthma and over $6 \%$ reported COPD [5].

In Brazil, about $10 \%$ of the population is estimated to have asthma, with over $40 \%$ of asthma-related hospitalizations being in children under 6 years, and 2500 death annually because of this disease [6]. In 2012, the Federal Government of Brazil created the program Farmácia Popular (Popular Pharmacy) to expand access to medicines for the most common diseases among citizens. Asthma was one of the diseases included in this program, which provides free distribution of drugs to the population [7]. As a consequence, production and sales of Orally Inhaled Products (OIDPs) in Brazil are growing and more companies are trying to enter the market, especially in the generic space. Molecules currently available as respiratory drugs in Brazil include beclomethasone dipropionate (BDP), budesonide, fenoterol, fluticasone propionate, formoterol, ipratropium, mometasone furoate, salbutamol, salmeterol, terbutaline, and tiotropium.

In China, industrial air pollution, urbanization, smoking, and increased population longevity have been cited as contributing to the prevalence of asthma and COPD [8]. The use of inhaled corticosteroids is gaining broader public acceptance, and pressurized metered dose inhalers (pMDIs) with salbutamol, ipratropium bromide, and BDP are included on the National Essential Drugs list, along with aminophylline and theophylline tablets also used for asthma [9].

Respiratory diseases are a growing concern in India as well, due to a combination of factors including tobacco smoking, exposure to biomass-fuel smoke, and widely spread "mosquito coil" insect repellent burning [10]. Several types of capsule-based and multi-dose dry powder inhalers (DPIs) and pMDIs are available in India, with increasing popularity of fixed-dose combination inhalers (inhaled corticosteroids + long-acting $\beta 2$-agonists), such as budesonide+formoterol; fluticasone + salmeterol; and beclomethasone + salbutamol. Nevertheless, oral formulations such theophylline or salbutamol tablets are still the preferred choice despite their low efficacy and known side effects, but thanks to simplicity and low cost.

Patients in all countries would benefit from appropriate and affordable medications delivered by inhalation. Despite

acting beta agonist; NDA, New drug applicaiton; NIFDC, National Institute for Food and Drug Control (in China); OGD, Office of Generic Drugs (in US FDA/CDER); OIDP, Orally inhaled drug product; PBE, Population bioequivalence; PD, Pharmacodynamic; PDR, Provisions for drug registrations (in China); PK, Pharmacokinetic; pMDI, Pressurised metered dose inhaler; PQRI, Product Quality Research Institute (US based); RLD, Reference listed drug (in the US); SABA, Short acting beta agonist; SAC, Single actuation content; SEC, Subject expert committee (in India); SX, Salmeterol xinafoate; TRC, Technical review committee (in India); UF, University of Florida; US, United States growing economic and therapeutic interest in those products, however, the regulatory procedures and demonstration requirements that ensure access to effective, safe and highquality products are diverse among world regions, are still evolving both procedurally and scientifically, and far from harmonized. This article summarizes scientific recommendations and requirements in the US, European Union, Brazil, China, and India for obtaining a government's authorization to market a "generic" version of an "original" orally inhaled or drug product. In some regions, "generic" is referred to as "second entry" or "subsequent" product; in this article it is termed "Test" product. The "original" may be referred to as "brand-name product", "ethical product", “innovator's product", or "reference listed drug (RLD)"; in this article it is termed "Reference" product. The high-level understanding that a "generic" is in some sense a "copy" of the "original" applies across all geographic regions, but precise definitions of what can be legally considered "original" and "generic" products depend on the country. Furthermore, the precise function of a "generic" (e.g., as a substitute, or a switch, or a replacement of the "original" product) also varies by the region, and this imposes further differences in the type and strictness of scientific recommendations and requirements aiming to prove that the "generic" is the same as the original, since "sameness" depends on the context. To provide such context, the article also provides an overview of the relevant elements for the regulatory systems in the five regions under consideration.

The overall systems for bringing generic orally inhaled drugs to the market bear some similarities across countries, but they also have important differences due to the unique cultural, historical and economic circumstances of each region. Even in the United States (US) and Europe, where the degree of resemblance is the highest and the regulatory recommendations and requirements are developed in relatively great detail, scientific challenges and differences in approaches exist within and between regulatory agencies.

This article is based on presentations given at the IPACRS and the University of Florida 2014 conference. The article is the result of a collective work of authors each specializing in a particular area. Specific regional perspectives were provided as follows: Sau L. Lee and Bhawana Saluja for the US; Alfredo Garcia Arieta for the EU; Gustavo Mendes Lima Santos for Brazil; Ying Li with Sarah Lu and Shuguang Hou for China; Juliet Rebello with colleagues Abhijit Vaidya, Jaideep Gogtay, Shrinivas Purandare for India; while Svetlana Lyapustina provided the overall integration of different inputs. Although this article focuses on OIDPs, the EU section also highlights some aspects of EU bioequivalence requirement for nasal drug products due to their similarity to those for OIDPs.

\section{US FDA PERSPECTIVE (BY SAU L. LEE AND BHAWANA SALUJA)}

\section{Regulatory Approach in the US}

In the US, a generic drug product must be shown to be therapeutically equivalent to a designated RLD. Therapeutically equivalent drug products have the same clinical efficacy and safety profiles when administered to patients under conditions specified in 
the labeling, and thus can be substituted for each other without any adjustment in dose or other additional monitoring. To obtain approval of a generic drug product, an Abbreviated New Drug Application (ANDA) submitted to the US Food and Drug Administration (FDA) Office of Generic Drugs (OGD) should contain data demonstrating pharmaceutical equivalence [per 21 CFR 320.1 (c)] and bioequivalence (BE) [per 21 CFR 320.1 (e)] of the proposed generic product to the designated RLD.

For the majority of orally administered drugs that reach their site(s) of action through the systemic circulation, BE is demonstrated based on drug concentration in a relevant biologic fluid (e.g., plasma or blood). However, this approach is currently considered inadequate in the US to establish BE of inhalation products intended for local action, such as pMDIs and DPIs that are used for treatment of lung diseases (e.g., asthma and COPD), since their drug delivery and intended action in the lung does not rely on the systemic circulation. Therefore, demonstration of BE for these locally acting drug products is challenging.

To meet this challenge, FDA developed an aggregate weight-of-evidence approach, which utilizes 1) in vitro studies, 2) pharmacokinetic studies, and 3) pharmacodynamic or clinical endpoint studies, to establish BE of inhalation products. As a result of this development, FDA published its first product-specific recommendations for a pMDI and a DPI in April and September 2013, respectively [11, 12]. This section further discusses a scientific framework for the aggregate weight-of-evidence approach, as well as formulation and device considerations for developing generic inhalation products for the US market. As a specific example, DPIs containing long-acting $\beta$-agonists and corticosteroids are used to illustrate the key concepts [13].

\section{Bioequivalence Studies for Inhalation Products in the US}

\section{In Vitro Studies}

For inhalation products, the relevance of in vitro studies to in vivo performance is not fully understood yet. Nevertheless, in vitro studies are considered useful in the $\mathrm{BE}$ evaluation, because they are generally less variable and more sensitive compared in vivo studies in detecting product performance differences. The key in vitro studies for BE assessment of DPIs include single actuation content (SAC) and aerodynamic particle size distribution (APSD). These comparative in vitro studies are described below.

- Most DPIs are multi-dose products, where the formulation is contained either in a reservoir compartment inside the device, or in pre-metered singledose blisters. The device material and formulation properties may differ between the Test and Reference products, and can affect differently the DPI in vitro performance during repeated use (e.g., due to a potential difference in accumulation of electrostatic charge over time) [14]. Therefore, it is important to demonstrate equivalence of SAC and APSD at multiple stages of product life, including the beginning, middle (for ED only), and end lifestages. For instance, based on the labeled number of inhalations, beginning lifestage may represent the first inhalation(s), middle lifestage may represent the inhalation(s) corresponding to $50 \%$ of the labeled number of inhalation(s), and end lifestage may represent the inhalation(s) corresponding to the labeled number of inhalations.

- Passive DPIs utilize breath-actuated devices, which operate over a range of patient's inspiratory flow rates. In addition, in vitro performance for passive DPIs can vary with flow rates [15]. Thus, it is important to demonstrate equivalence of SAC and APSD at different flow rates (i.e., minimum of three flow rates). The flow rates selected for in vitro testing of SAC and APSD are expected to reasonably reflect those generated by the relevant patient population. For example, the flow rates for in vitro testing of a Test DPI referencing Advair ${ }^{\circledR}$ Diskus should include 30, 60 (reference labeled flow rate) and $90 \mathrm{~L} / \mathrm{min}$.

- To ensure that the targeted patients can operate the Test DPI device effectively and receive proper medication without any significant change in their inspiratory effort compared to use of the Reference DPI, it is preferable that the device resistance of a Test DPI be comparable to that of the Reference DPI. It has also been suggested that the use of a Test DPI with a comparable air flow resistance to the Reference DPI is expected to increase the likelihood of establishing SAC and APSD equivalence at different flow rates [16].

\section{US Approach to Pharmacokinetic Studies}

OIDPs are intended for drug delivery to the sites(s) of action in the lung, but drug deposited in the target region of the lung or in the oropharyngeal region (i.e., drug absorption of the swallowed fraction through the gastrointestinal tract) may also enter the systemic circulation. A comprehensive understanding of the relevance for this downstream process (i.e., drug entering the systemic circulation from an inhalation route) to local drug delivery in the lung is currently lacking. Nevertheless, measuring drug concentration in the systemic circulation (i.e., plasma or blood) is relevant to BE of DPIs because of possible systemic side effects of orally inhaled drugs.

The study design for a pharmacokinetic (PK) BE study for inhalation products is similar to that used for solid oral dosage forms. Such a study is generally based on administration of a single dose in healthy subjects. PK data from healthy subjects are generally less variable than those from patients, which may be associated with various sources of variability related to the patients' disease condition. Therefore, the outcome from the PK BE study conducted in healthy subjects are expected to provide a more reliable and sensitive measure for detecting differences in drug product characteristics, which may affect $\mathrm{BE}$ of Test and Reference inhalation products. In addition, the dose for the PK study is typically selected based on minimizing the number of actuations/ inhalations (preferably no more than the single maximum labeled adult dose), but assuring suitable assay sensitivity.

Equivalence in systemic exposure of Test and Reference inhalation products is based on the natural log-transformed 
area under the curve (AUC) and peak concentration $\left(\mathrm{C}_{\max }\right)$ data using the average BE approach [17]. Generally, two inhalation products are considered PK-equivalent if the $90 \%$ confidence intervals of the geometric mean ratios for AUC and $\mathrm{C}_{\max }$ fall within $80.00-125.00 \%$

At the present time, the relationship among PK dose proportionality across multiple strengths of OIDPs, in vitro performance parameters (e.g., SAC and APSD for DPIs) and product characteristics (e.g., formulation) are not well understood; therefore, a PK BE study is generally necessary for all strengths for OIDPs containing multiple strengths (such as Advair ${ }^{\circledR}$ Diskus).

\section{US Approach to Pharmacodynamic or Clinical Endpoint Studies}

The in vitro and PK studies provide substantial weightof-evidence to support equivalent product performance. However, due to incomplete understanding of the relevance of results from these BE studies to drug concentrations at the local site(s) of action in the lung, there may still be residual uncertainties regarding the sufficiency of in vitro and PK data for establishing $\mathrm{BE}$ of inhalation products. Therefore, an additional pharmacodynamic (PD) or clinical endpoint (CE) study is currently considered necessary to support BE of these locally acting drug products.

Historically, a PD study is generally preferred over a CE study. Such a PD study provides greater sensitivity to detect potential differences in local drug delivery in the lung as compared to a CE study, provided that an adequate doseresponse relationship is demonstrated within the study. For short-acting $\beta$-agonists (SABAs), bronchodilatation and bronchoprovocation models based on lung function testing, when properly designed, show an adequate dose-response relationship [18, 19]. Based on these two PD models, FDA approved four generic chlorofluorocarbon (CFC)-based albuterol pMDIs in the mid-1990's.

However, unlike SABAs, there are currently no established models that can demonstrate an adequate doseresponse relationship for inhaled corticosteroids (ICS) (e.g., fluticasone propionate, FP) and long-acting $\beta$-agonists (e.g., salmeterol xinafoate, SX). An FDA-sponsored study conducted by the National Jewish Health (NJH) medical center indicated that using a PD model based on exhaled nitric oxide (eNO) (initially considered as a promising biomarker for establishing dose-response for ICS), generated a shallow dose-response relationship for FP (Fig. 1), with the lowest daily dose $(88 \mathrm{mcg}$ from Flovent ${ }^{\circledR}$ HFA) on the flatter portion of the dose-response curve. In addition, not all patients enrolled in the NJH study exhibited a clear dose-dependent decrease in the eNO levels (data not shown). Similar results were observed for approved doses of SX (50 mcg salmeterol for DPIs and $42 \mathrm{mcg}$ salmeterol for pMDIs), using either bronchodilatation or bronchoprovocation PD model [20, 21]. As a result, for the inhalation product containing an ICS and/or a LABA, a CE study should be used to support bioequivalence as part of the weight-of-evidence approach. The key features of such a CE study are described in the FDA draft BE guidance for FP/SX DPI referencing Advair ${ }^{\circledR}$ Diskus [11]. In that guidance, the CE study is conducted in asthmatic patients. It is based on a multicenter, randomized, parallel group design consisting of a 2-week

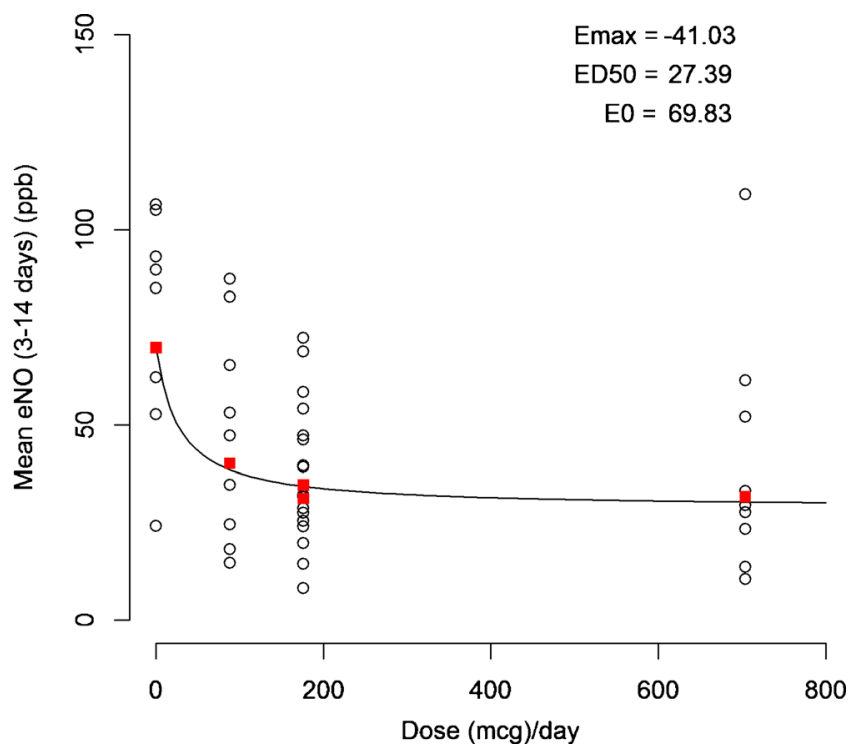

Fig. 1. Mean eNO response as a function of daily dose of FP. Data collected through an FDA sponsored study with National Jewish Health Center in which nine subjects completed the study. The eNO data were fitted by the $E_{\max }$ model described by $E_{R}=E_{O R}+\left(E_{\max R}\right.$ * $\left.D_{R}\right) /\left(E D_{50 R}+D_{R}\right)$, where $E_{R}=$ response, $D_{R}=$ administered dose, $E_{O R}=$ placebo response in the absence of the drug, $E_{\max R}=$ fitted maximum drug effect, and $E D_{50 R}=$ dose required to produce $50 \%$ of the fitted maximum effect

run-in period followed by a 4-week treatment period of the placebo, Test and Reference product. The use of placebocontrol ensures sensitivity of the study by demonstrating a significant difference $(\mathrm{p}<0.05)$ between the placebo-control group and each of the two treatment groups containing Test and Reference products. In an attempt to further optimize the sensitivity of the study to detect potential differences between the Test and Reference products, the CE study is conducted at the lowest labeled recommended dose of $100 \mathrm{mcg}$ FP and 50 mcg salmeterol powder for inhalation twice daily for the Test and Reference products.

The FDA draft FP/SX DPI BE guidance [11] suggests two clinical endpoints to support BE of the FP and SX components. Demonstration of equivalence for the SX component is based on the area under the serial $\mathrm{FEV}_{1}$-time curve calculated from time zero to 12 hours $\left(\mathrm{AUC}_{0-12 \mathrm{~h}}\right)$ on the first day of the treatment. Since the FP component does not affect the $\mathrm{FEV}_{1}$ on the first day of treatment, the $\left(\mathrm{AUC}_{0-12 \mathrm{~h}}\right)$ relative to a pretreatment baseline on the first day of treatment is considered to be contributed by the SX component alone. An additional clinical $\mathrm{BE}$ endpoint is based on $\mathrm{FEV}_{1}$ measured in the morning prior to the dosing of inhaled medications on the last day of a 4week treatment period. The treatment duration of four weeks was chosen because the mean change from baseline in pre-dose $\mathrm{FEV}_{1}$ reached steady state approximately at Week 4 following treatment with Advair ${ }^{\circledR}$ Diskus [22]. The change from baseline in pre-dose $\mathrm{FEV}_{1}$ at Week 4 can be considered to be contributed by both FP and SX components of the drug product. Provided that both the Test and Reference treatment groups demonstrate superiority to the placebo-control group, the Test and Reference products are equivalent in the CE study if the $90 \%$ confidence intervals of the Test/Reference ratios for the two endpoints described above fall within $80.00-125.00 \%$. 


\section{Device and Formulation Recommendations in the US}

DPI devices currently marketed in the US may differ considerably with respect to their interior design, appearance, and external operating principles. Thus, to help ensure switchability of Test and Reference DPIs from a patient's perspective, the design of Test DPI device warrants consideration of the effect of design factors, such as energy source (e.g., active or passive (breath-actuated) device), metering principle (e.g., pre-metered multi-dose, device-metered multidose or pre-metered single dose units), number of doses, external operating principle, shape and size, on the patient handling relative to the Reference DPI device.

Formulations of the currently approved DPIs are made of either the active pharmaceutical ingredient (API) alone or the API associated with a carrier such as lactose. Additional inactive ingredient(s) (e.g., magnesium stearate) may also be used. The nature of inactive ingredient(s) used in the DPI formulation can significantly affect the product performance and local safety (e.g., irritability in the respiratory tract). The choice of inactive ingredient(s) in a Test DPI is critical to establish BE to the Reference DPI and safety. For the above reasons, it is important that the formulation of the Test DPI, at a minimum, be qualitatively $\left(\mathrm{Q}_{1}\right)$ the same (i.e., the same inactive ingredient(s)) as the Reference DPI.

The Test DPI may use a formulation that is quantitatively $\left(\mathrm{Q}_{2}\right)$ different from the Reference DPI. For example, the internal design of the Test DPI device (e.g., the dimension and shape of channels) may differ from that of the Reference DPI because the Reference DPI device may be proprietary to its sponsor or protected by a patent. Since the DPI performance is influenced by both formulation and device characteristics, a drug-to-excipient ratio in the Test formulation may be one of the important design variables needed to be adjusted in order to achieve equivalence to the Reference product. These possible $\mathrm{Q}_{2}$ and device differences need to be justified by in vitro and in vivo BE studies to show that they do not affect the safety and efficacy of the Test DPIs.

\section{Further Research in the US}

The FDA has developed a weight-of-evidence approach that emphasizes in vitro studies, PK studies and PD or $\mathrm{CE}$ studies to establish BE of locally acting OIDPs. This approach is considered sufficient to demonstrate BE for these locally-acting drug products. Nevertheless, in an effort to explore alternative methodologies to establish BE for inhalation products and to facilitate the development of highquality generic versions of these complex drug products, the FDA, as part of Critical Path initiatives and Generic Drug User Fee Amendments (GDUFA) Regulatory Science Research Program, sponsored a research study to investigate if PK studies are capable of providing information on the fate of inhaled drugs in the lung, specifically the relationship between the regional lung deposition of the inhaled drug and its time-dependent drug concentration in plasma. This research was based on the emerging hypothesis that PK may be related to the lung deposition of poorly soluble orally inhaled drugs that have very low bioavailability (e.g., FP). Specifically, it has been proposed that for such poorly soluble orally inhaled drugs, PK parameters, such as AUC and $\mathrm{C}_{\max }$, may be related to the central-to-peripheral drug deposition ratio in the lung. If successful, for the class of poorly soluble orally inhaled drugs, the CE study may not be needed in the weight-of-evidence approach, without compromising the efficacy and safety of test inhalation products.

\section{A EUROPEAN PERSPECTIVE ON ORALLY INHA LED AND NASAL “GENERIC / HYBRID” PRODUCTS (BY ALFREDO GARCIA ARIETA)}

\section{Regulatory Pathways in Europe}

The legislation of the European Union (EU) on pharmaceutical product assessment and authorisation establishes that a product can only be rejected if it is a potential serious risk for public health [23, 24]. For products such as a generic or hybrid product, which claim to be equivalent to the Reference product, a potential serious risk for public health is considered to exist if demonstration of equivalence fails [24]. However, a product's "switchability" (or interchangeability, or substitutability) is out of the scope of the EU legislation, since it is a matter of national competence, i.e., to be decided by national authorities of individual European countries [25]. Approval can be granted if the product is "prescribable" with a positive benefit-risk relationship. Once these "prescribable" products are on the market, the national regulatory authorities may have a difficult task of deciding if these are "switchable" with the Reference product and between similar "prescribable" products. Nevertheless, a failure to show "interchangeability" cannot be a reason to reject the marketing authorisation of a pharmaceutical product. In summary, then, there is a two-step process in Europe. The first step, at the EU level, is to decide whether a product is prescribable due to its positive benefit-risk balance. The second step, at the national level, is to decide whether the product is switchable (or interchangeable) with other products in that national market. In the case where a "generic" is approved but not deemed switchable, it can be marketed but not substituted or interchanged with other products, so it would have to be specifically prescribed by a physician.

In the EU, "generic products" are not required to be equivalent to the Reference product in every respect, but they must demonstrate bioequivalence to the Reference product by means of pharmacokinetic (PK) bioavailability studies, or else be waived from this PK demonstration [23]. Those products that demonstrate equivalence by means of pharmacodynamic (PD) or clinical endpoints, or that are waived from such demonstration, are classified as "hybrids" [23]. This classification does not directly address the "interchangeability" of the product, but rather focuses on the methodology that is employed to show therapeutic equivalence. Neither the prescriber nor the patient is informed whether a product was approved as a "generic" (via PK equivalence) or as a "hybrid" (which may mean it failed PK equivalence).

Locally acting products, such as orally inhaled drug products (OIDPs) are typically submitted for approval as "hybrid" applications because traditionally it had been believed that equivalence can only be shown by means of clinical or PD endpoints. More recently, however, 
pharmacokinetics has proven to be sufficiently discriminating for some locally acting products and therefore in vitro data or PK data are being used instead of PD data. As a consequence, "generic OIDPs" do not exist in the EU in a strict legal sense; they are all "hybrid OIDPs" under current regulations [23]. Even if approved based on in vitro data or PK data (with clinical studies waived), these are hybrid drugs rather than generics, per the EU definitions.

\section{Bioequivalence Requirements in the EU}

For locally acting products, a step-wise approach similar to that employed in systemically acting products is applied in the European Union (Fig. 2). In some cases, an in vitro approach may be enough to demonstrate therapeutic equivalence (e.g., solutions for nebulization with the same qualitative and quantitative composition). If this approach is not possible, the most sensitive endpoint is the use of PK studies to assess systemic safety and lung deposition. Finally, if bioequivalence cannot be shown in this second step based on PK studies, the third step consisting of PD or clinical studies can be conducted to obtain a marketing authorization (see Figs. 2 and 3).

Traditionally, systemic exposure has not been considered as indicative of the bioequivalence of locally acting products because the plasma levels, if any, are downstream from the site of action. This is in contrast to systemically acting drugs, where the drug arrives to the site of action from the blood and, therefore, if plasma concentrations are similar, concentrations at the site of action will be similar. Therefore, for locally acting products, therapeutic equivalence had to be shown by means of PD or clinical endpoints. However, the fact that the plasma concentrations are downstream from the site of action is not invalidating the drug plasma levels as indicative of the drug levels at the site of action per se. If the drug absorption from the site of action is not saturated, and if the swallowed fraction is negligible or is blocked, the plasma

\begin{tabular}{|c|c|c|c|}
\hline STEP & $\begin{array}{l}\text { SYSTEMICALLY } \\
\text { ACTING DRUGS }\end{array}$ & $\begin{array}{c}\text { LOCALLY ACTING } \\
\text { DRUGS } \\
\text { (EMA) }\end{array}$ & $\begin{array}{l}\text { WEIGHT OF } \\
\text { EVIDENCE } \\
\text { APPROACH } \\
\text { (FDA) }\end{array}$ \\
\hline Step 1 & $\begin{array}{l}\text { Biowaivers } \\
\text { based on BCS } \\
\text { or dosage forms } \\
\text { in solution }\end{array}$ & $\begin{array}{l}\text { In vitro comparison } \\
\text { OR }\end{array}$ & $\begin{array}{c}\text { In vitro } \\
\text { comparison } \\
\text { AND } \\
\end{array}$ \\
\hline Step 2 & $\begin{array}{l}\text { Conventional PK } \\
\text { BE } \\
\text { Surrogate of PD }\end{array}$ & $\begin{array}{l}\text { PK BE for safety } \\
\text { and lung } \\
\text { deposition } \\
\text { OR }\end{array}$ & $\begin{array}{c}\text { PK for systemic } \\
\text { safety } \\
\text { AND }\end{array}$ \\
\hline Step 3 & $\begin{array}{l}\text { PD / Clinical } \\
\text { endpoints } \\
\text { (Therapeutic } \\
\text { equivalence) }\end{array}$ & $\begin{array}{l}\text { Relative potency } \\
\text { PD / Clinical } \\
\text { endpoints for } \\
\text { efficacy or safety }\end{array}$ & $\begin{array}{c}\text { Relative potency } \\
\text { PD / Clinical } \\
\text { endpoints for } \\
\text { efficacy }\end{array}$ \\
\hline
\end{tabular}

Fig. 2. Stepwise approach employed in the European Union for systemically acting products and locally applied and locally acting orally inhaled products in comparison to the weight of evidence approach employed in the US-FDA for orally inhaled drug products. The background indicates the legal basis of the application: dotted background for generic applications and striped background for hybrid applications. "Relative potency" refers to the dose-scale analysis of the dose-response curve

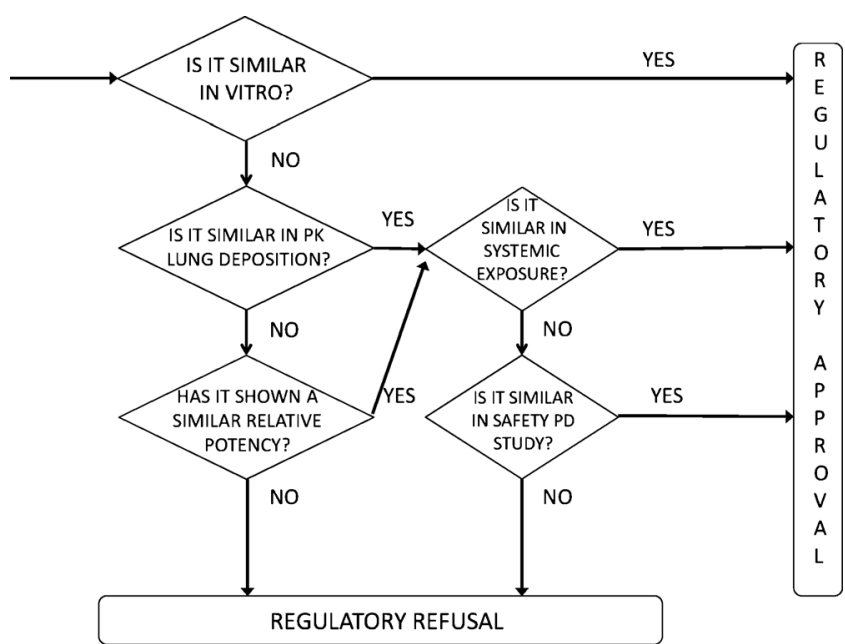

Fig. 3. Decision tree for the development and regulatory assessment of orally inhaled products in the European Union. "Relative potency" refers to the dose-scale analysis of the dose-response curve

concentrations downstream would be a reflection of what is happening at the site of action. In fact, the PD or therapeutic effect is used as an indicator of the levels at the site of action, although it is downstream of the signal transduction process [26]. Therefore, the CHMP guideline [27] considers that plasma concentrations might be indicative of the concentrations at the site of action. In addition, plasma levels are more sensitive than the PD or clinical endpoints and, thus, acceptable as surrogates of therapeutic equivalence.

\section{Step 1: In Vitro Approach in the EU}

Generics are approved based on in vitro data where they are considered as a minor variation of the Reference product, since variations of the Reference product are sometimes approved without the need of in vivo studies. Ideally, in vitro testing should mimic in vivo conditions (e.g., with realistic inlet ports and flow profiles), but this is not essential, since from the regulatory perspective, what is of most interest is the discriminatory power for a comparison in relative terms even if the methodology lacks predictive power in absolute terms (e.g., prediction of regional deposition, because it is assumed to be similar for Test and Reference products whatever it is in absolute terms).

It has been claimed that an in vitro acceptance range of $\pm 15 \%$ is extremely strict for the analysis of the aerodynamic particle size distribution based on individual stages or groups of stages, because it is not possible to demonstrate equivalence between two different batches of the Reference product [28]. However, it must be understood that this occurs because there is a large inter-batch variability and this can be compensated by increasing the sample size without any ethical limitation, in contrast to in vivo studies. In addition, the in vitro comparison applies to the mean of the Test batches with the mean of the Reference batches. For these reasons, some EU regulators recommend that a sufficient number of batches be tested (probably more than three) in order to compensate for the inter-batch variability and obtain representative mean values.

Solutions for nebulization: If the composition is qualitatively and quantitatively identical, approval can be granted 
based on physicochemical similarity (e.g., viscosity, $\mathrm{pH}$ ). If the composition is qualitatively or quantitatively different, more extensive in vitro testing is necessary and should be conducted using the nebulizer described in the labeling of the Reference product, if any. This in vitro comparison should include droplet size distribution, which should be conducted taking into account the potential difference in hygroscopicity, and nebulizer efficiency, which may differ simply due to the presence of surfactants / preservatives [29].

Suspensions for nebulizations: In addition to the requirements described above for solutions for nebulization, it is necessary to demonstrate sameness in crystallography and similar particle size distribution of the particles in suspension (which is accepted as a surrogate for in vivo dissolution of OIDPs in the EU) and similar aerodynamic particle size distribution (APSD) of the nebulized droplets.

Pressurized metered dose inhalers (pMDIs) in solution or suspension: In vitro requirements are mentioned in the OIDP guideline [27], but detailed tests are not described. Therefore, it is convenient to complement the comparison with some of the in vitro tests for nasal products described in the FDA draft guidance for industry [30]. A solution-based pMDI has been approved in Spain based on in vitro data only [31], but suspension pMDI or DPI applications based only on in vitro data have not yet been submitted in Spain.

For nasal products, the in vitro tests described in the FDA draft guidance [30] are acceptable In the European Union. Unlike FDA guidance recommendation [30], however, all in vitro comparisons in the EU should be based on average bioequivalence instead of population bioequivalence statistical approach. An acceptance range of $\pm 15 \%$ is considered acceptable by default.

\section{Step 2: PK Approach in the EU}

In the EU, PK bioequivalence studies are considered an acceptable methodology to assess the extent of lung deposition of the inhaled drugs and the pattern of deposition within the lungs, when the contribution of the swallowed fraction is negligible or made negligible by e.g., active charcoal blockage. The efficacy profile can be assumed to be equivalent if the lung deposition is shown to be equivalent.

The total dose absorbed into the blood from the lungs (area under the curve, or AUC) reflects the dose that has reached the lungs, since absorption from the lung is not saturated. Importantly, the fraction removed by mucociliary clearance that is not available for binding the receptors is also not available for absorption. In addition to the total dose, the pattern of deposition within the lungs is also relevant for efficacy, and therefore equivalence in AUC is not sufficient to ensure equivalent local efficacy and local safety. As the particles deposited in the lungs' periphery are absorbed with relatively short $\mathrm{T}_{\max }$ values (e.g., 2-3 minutes for some drugs), and the particles deposited in the central lung require more time depending on whether the drugs is administered as a solid (e.g., DPI powder particles) or as a solution (e.g., solution-based pMDI), and depending on the drug lipophilicity and dissolution rate, the $\mathrm{C}_{\max }$ and $\mathrm{T}_{\max }$ can provide information on the pattern of distribution. This information is more discriminating than any other PD or clinical endpoint available for inhaled corticosteroids. For example, to demonstrate an approximate 2-fold difference in efficacy between QVAR (HFA beclomethasone) and Becotide (CFC beclomethasone), over 300 subjects were required in a PD study [32], but only 18 subjects in a PK study [33].

In some cases, a single PK study can be used for both efficacy and safety because the drug is not absorbed in the intestine (e.g., ipratropium, tiotropium, cromoglycate, nedocromil), or despite being absorbed, first-pass effect is almost complete (e.g., beclomethasone, fluticasone, ciclesonide) or the absorption is so quick (e.g., $\mathrm{T}_{\max }=5 \mathrm{~min}$ ) that the lung absorption occurs before the gastrointestinal absorption has started after gastric emptying (e.g., salbutamol/albuterol, salmeterol). In the case of salmeterol, some European regulators have accepted $\mathrm{AUC}_{0-30}$ min as a surrogate for efficacy and $\mathrm{AUC}_{0-\mathrm{t}}$ for safety. In drugs with significant oral bioavailability (e.g., budesonide), a PK study with active charcoal is necessary to assess efficacy, and another study without charcoal is used to assess safety. Charcoal blockade has to be validated to demonstrate that oral contribution to total bioavailability is negligible.

Most respiratory products are now being approved in the EU based on PK studies (e.g., nasal sprays of mometasone in suspension; pMDI in suspension of salbutamol, salmeterol, fluticasone and salmeterol/fluticasone; and DPI of salmeterol/ fluticasone).

\section{Step 3. PD Approach in the EU}

The bronchodilation and the bronchoprovocation models seem to be applicable for bronchodilators [18, 34], although the bronchoprovocation protocol available for short acting agents may require some minor modifications for formoterol [35]. In contrast, for salmeterol, the absence of assay sensitivity in the therapeutic dose range makes PD studies insensitive to detect any difference between inhalation products. Consequently, in the EU, the approval of secondentry salmeterol products should be based on step 1 or step 2 described above.

Similarly, assay sensitivity seems absent in corticosteroids. Any PD or clinical endpoint showing a sufficiently steep dose-response curve would therefore be welcome. Ideally, the PD endpoint/marker should reflect inflammation. The following methods described in the literature would be acceptable in the EU: methacholine $\mathrm{PD}_{20}[36,37]$, exhaled NO [38], sputum eosinophilia [39, 40] and even the unspecific $\mathrm{FEV}_{1}$ [41, 42]. Some limited experience suggests that the model based on methacholine $\mathrm{PD}_{20}$ could be used if patients are selected who are able to respond differently to the two dose levels of the drug [43]. A cross-over design should be employed to reduce variability, although the European guideline states that in principle a parallel design is preferable [27].

In contrast to the weight-of-evidence approach advocated by the US FDA, according to which both in vitro data and PK safety have must demonstrate equivalence [11], the EU step-wise approach allows approval based only on the PD or clinical endpoint equivalence if the in vitro and/or PK studies fail to show equivalence. Consequently, the demonstration of assay sensitivity is of critical importance, at least to some European regulators. The EMA guideline [27] requires both the dose-scale analysis (i.e., relative potency) and the 
response-scale analysis. Some EU reviewers, however, may place less emphasis on the dose-scale analysis (in part because it is less precise) or prefer to use a response-scale analysis since it is the method used for new chemical entities.

In the case of fixed combination of two bronchodilators, the use of PD endpoints cannot ensure equivalence in both components, and therefore only step 1 (in vitro) or step 2 (PK) can be used for equivalence demonstration. In the case of fixed combinations of a bronchodilator and a corticosteroid, endpoints should be specific for each of the components, or a single-dose study should be conducted for the bronchodilator (since the corticosteroid has no bronchodilator effect at single dose), and a multiple-dose study for the corticosteroid where all treatment groups receive the same dose of bronchodilator. The efficacy of the inhaled corticosteroid should be measured when the contribution of the long-acting bronchodilator is negligible (i.e., later than at least 12 hours after the last administration, e.g., at 24 hours).

Requiring a clinical study at one- or two-dose levels where it is known that there is no dose-response curve and, therefore, the study lacks the necessary assay sensitivity, in order to simply obtain supportive evidence, does not seem ethically acceptable at least to some EU regulators. Finally, for multi-strength products, if equivalence is shown in step 3, equivalence for the other strengths must be conducted by means of in vitro data (step 1) or PK data (step 2).

\section{Remaining Challenges in the EU}

There are several remaining scientific challenges and unresolved differences in approaches among European regulators, for example:

- For comparing APSDs, the European guideline [27] accepts stage pooling if justified, but since IVIVC is not well established, some countries may prefer not to pool stages and compare all stages individually.

- When comparing the flow rate dependency of DPIs in order to justify the use of healthy volunteers in PK studies, a visual inspection of a flow rate dependency plot for both Test and Reference products (e.g., Fine Particle Dose vs flow rate, for at least three flow rates) is currently the only method employed, and some countries may even ignore this requirement. In principle, the flow rate dependency can be different as long as the trend is the same in both Test and Reference products, so it is possible to assume that the difference will be the same at all inspiratory flow rates. The same criteria need to be applied to conclude that different strengths of the Test product exhibit the same flow rate dependency.

- In order to conclude that the different strengths of the Test and the Reference product exhibit proportional APSD, it may be necessary to compare all individual stages, at least their mean values, although some countries only compare the fine particle mass.

- In vitro variability between batches of some Reference products or within a single batch of some Reference products through their storage period may be so large that demonstration of PK bioequivalence based on the OIDP guideline required approach, even among batches of the same Reference product, may not be possible. Therefore, some regulators suggest that before the in vitro comparison, several batches of both Test and Reference products could be tested to identify representative batches (within $\pm 15 \%$ of their corresponding median). In case of fixed combinations, this may require, if pre-specified in the protocol, the use of different batches for each active ingredient.

- The development of an IVIVC may be useful to correct the results of the PK study to the mean values of the in vitro specifications and to define product specifications capable of ensuring APSD equivalence in the entire range observed for the Reference product. How to develop this level of IVIVC and to correct the data is under debate. Another novel approach that might be acceptable to obtain marketing approval in Europe could be to show that the socalled "side" batches at the extremes of the Test product's specifications range are not superior and not inferior to the "side" batches at the extremes of the Reference product's distributions for relevant quality attributes (e.g., as inferred from measurements on units from multiple batches of the Reference product obtained from the market).

- An active charcoal blockade should be able to make gastrointestinal (GI) absorption negligible (e.g., $<5 \%$ ). Therefore, the higher GI contribution to systemic absorption, the more efficacious the blockade needs to be. In addition, while it is often assumed that a low oral bioavailability is sufficient demonstration of negligible GI contribution, in case of inhaled drugs, the GI contribution also depends on the inhaled fraction. If the inhaled fraction is low (e.g., $10 \%$ of the total emitted dose), then even assuming $100 \%$ lung bioavailability, a 1\% GI bioavailability of the rest of the administered dose (90\%), which is swallowed, represents $8.26 \%$ of the total systemic exposure (namely $10 \%$ lungs $+0.9 \%$ GI). This consideration, unfortunately, seems to be largely ignored even by the innovator companies when developing new active substances.

- The main PD challenge in the EU is to make assessors aware that the classical comparison of the response in the response-scale is not adequate for "generics" [44], once they have acknowledged that at least two dose levels need to be tested [27]. It is also necessary to understand that for fixed-dose combinations of a LABA and an ICS, a third-arm control group with ICS alone is not adequate to show assay sensitivity because it only demonstrates that the LABA is better than placebo, and that does not give any information about the combination LABA+ICS that is under comparison (Test vs. Reference). Therefore, showing equivalence in the responsescale analysis does not ensure equivalence because the design is probably unable to detect a 2-fold or 4fold difference in the ICS component as already known, although the exacerbation rate after 1 year might double [45]. Similarly, it is essential to understand that superiority to placebo is not a 
demonstration of assay sensitivity despite what is stated in ICH E10 [46], which is written for new active substances. For demonstration of equivalence in "generics", assay sensitivity is the ability to detect differences between adjacent doses [35].

- For pediatric drug product development (for generic versions of drugs that include children as target populations), further consensus-building is necessary. Some countries would like to duplicate the entire product development for children, while other countries do not require any additional study, or are satisfied with a small PK safety study in pediatric patients as a bridging study to confirm the equivalence demonstrated for adults.

\section{ANVISA PERSPECTIVE (BY GUSTAVO MENDES LIMA SANTOS)}

\section{Overview of Regulatory Requirements in Brazil}

Anvisa, the Brazilian government agency responsible for regulation, evaluation and surveillance of medicinal products, has published resolutions that define two scenarios for the registration of inhaled generic medications [47, 48]:

- For solution pMDIs and solution-based nebulizers, pharmaceutical companies must present in vitro studies as evidence of therapeutic equivalence;

- For pMDI suspensions, suspension-based nebulizers and DPIs, results of both in vivo and in vitro studies must be presented.

However, Anvisa has not provided acceptance criteria or other details for these studies. In 2005, Anvisa established a Cooperation Term with Panamaerican Health Organization (PAHO) in order to broaden the debate and encourage the publication of a guidance for in vitro and in vivo comparability tests of nasal and inhaled drug products [49]. In the 2000s, PAHO funded research activities, initiated workshops and technical visits that allowed researchers from Brazilian and international universities, regulatory authorities from different agencies, and representatives of the pharmaceutical industry to interact. From these interactions, it was decided to first develop a guidance for intranasal products and subsequently develop a guidance for orally inhaled drug products (OIDPs). In 2009, Anvisa published a guidance specifying requirements for demonstrating equivalence between nasal products [50]. This guidance includes in vitro tests and PK studies to demonstrate in vivo bioequivalence, while clinical studies can serve as a substitute. However, development of the OIDPs guidance was stopped at that time because of significant knowledge gaps. These included lack of studies that showed in vitro and in vivo correlations leading to uncertainty about the ability of in vitro tests to predict efficacy and safety. At the same time, there were some conceptual differences between major international regulatory agencies that resulted in different strategies for approving generic OIDPs. In 2011, a new working group was formed by Anvisa to restart the "OIDPs comparability" project. In addition, research studies have been initiated with the purpose of filling knowledge gaps that will ensure that the guidance is based on solid scientific principles. Due to the need for affordable inhaled medications for the therapy of pulmonary diseases in Brazil, Anvisa is currently advising pharmaceutical companies on a one-by-one consultation basis, to ensure that submission documents include relevant in vitro and in vivo studies.

Accoding to Anvisa, generic OIDPs must:

- Contain the same API at the same dose as the reference drug;

- Use similar excipients and polymorphic profile;

- Use the same dosage form (suspension or powder) with similar device handling characteristics;

- Demonstrate in vitro equivalence; and

- Demonstrate in vivo equivalence (for suspension or powder products).

Until a guidance with the final recommendations is published by the agency, companies should submit a protocol including in vitro and in vivo studies proposals, which are assessed by the Coordination of Therapeutic Equivalence committee. Some of the information verified by Anvisa's specialists during evaluation of protocols has already been published as a Technical Note and is available on Anvisa's website [51]. Current Anvisa recommendations for in vitro and in vivo tests are outlined in the next two sections. These recommendations, however, are not yet established as a Resolution, which is a final legal instrument used by Anvisa to regulate medicines in Brazil.

\section{In Vitro Studies Required in Brazil}

As a pre-requisite to being considered in vitro equivalent, two products should meet identical compendial or other applicable standard of identity, strength, quality, and purity. For OIDPs, those standards can be found in the United States Pharmacopeia (USP) and European Pharmacopeia (EP), as the Brazilian Pharmacopeia (BP), only describes general tests. Additionally, comparative in vitro tests are required (Table I) and the Population Bioequivalence (PBE) approach is suggested for comparison of results.

Table I. Comparative Performance Tests that Must be Part of an Oral pMDI or DPI Pharmaceutical Equivalence (PE) Submission in Brazil

\begin{tabular}{lll}
\hline & $\begin{array}{l}\text { Oral } \\
\text { pMDIs }\end{array}$ & Oral DPIs \\
\hline Performance tests & $\mathrm{X}$ & $\mathrm{x}$ \\
Priming and repriming & $\mathrm{X}$ & - \\
$\begin{array}{l}\text { Content of an operation over } \\
\quad \text { the total content of the device }\end{array}$ & $\mathrm{X}$ & $\mathrm{x}$ \\
$\begin{array}{l}\text { Aerodynamic particle size } \\
\quad \text { distribution by cascade impaction }\end{array}$ & $\mathrm{X}$ & $\mathrm{x}$ \\
$\begin{array}{l}\text { Particle / droplet size } \\
\quad \text { distribution by laser diffraction }\end{array}$ & - & - \\
$\begin{array}{l}\text { Emitted dose mass } \\
\text { Number of doses per device }\end{array}$ & $\mathrm{X}$ & $\mathrm{X}$ \\
$\begin{array}{l}\text { Spray pattern } \\
\text { P }\end{array}$ & $\mathrm{X}$ & - reservoir DPIs) \\
\hline
\end{tabular}


In addition, some recommendations about device activation, handling and design comparability are included in the Technical Note [51]. With regard to activation of devices, complete description of the steps for activation must be submitted to Anvisa prior to the conduction of any tests. After that, device activation instructions must be part of documentation for evaluation. The use of an automatic actuator system is obligatory for conducting certain tests, such as priming/repriming, dose content uniformity and spray pattern. The following information related to the actuator system must be provided to Anvisa:

i) Complete description of the automatic operation system (AOS) and, if present, its accessories;

ii) Description and specifications/acceptance criteria of the performance parameters that must be controlled in the automatic operation system and, if present, in its accessories, for each of the tests, in accordance with what is established by its manufacturerer; and

iii) Records of AOS controls performed prior and during conduction of each test.

Interaction between device and patient is critical for therapeutic performance of inhaler products, since different efforts and handling procedures may influence drug delivery. This patient-device interaction may depend on such characteristics as age, gender, disease and breathing cycle; and differences in patients' efforts or handling of the devices could compromise interchangeability of products. Anvisa requests, therefore, that applications include information addressing the following questions:

- Does the operation mechanism of the device exacerbate differences in patients' efforts and handling?

- Does the shape and dimension of the device exacerbate differences in patients' efforts and handling?

Evidence of similarities could be demonstrated in patient handling studies.

\section{In Vivo Studies Required in Brazil}

In addition to in vitro tests, Anvisa requires submission of in vivo studies to demonstrate that pulmonary deposition exhibits similarity. Confirmation of similarity in pulmonary deposition can be demonstrated through crossover PK studies, with the inhibition of absorption from the gastrointestinal tract through administration of activated charcoal (if necessary), such that the PK parameters obtained from the drug's blood concentration versus time curves are related to pulmonary deposition and absorption. For confirmation of safety, crossover PK studies without inhibition of absorption of the drug from the gastrointestinal tract would reflect the total quantity of the drug available systemically.

A product is considered in vivo bioequivalent if the extreme values at $90 \%$ confidence interval of the ratio of geometric means, the ratio of the Test and Reference products' area under the curve from time zero to time $\mathrm{t}\left(\mathrm{AUC}_{0-\mathrm{t}}\right)$ and the ratio of maximum concentration $\left(\mathrm{C}_{\max }\right)$ between the Test drug and the Reference drug are maintained within the interval of 0.8 -1.25 , for both safety and efficacy studies.
In some cases, due to the substance's characteristics (e.g., lack of sufficient assay sensitivity), PK studies are not possible. In this case, therapeutic equivalence of pulmonary and systemic effects can be demonstrated through PD or clinical studies. Biomarkers have to be directly related to product efficacy. In addition, it is necessary that a dose response is observed for the marker, as only under such conditions the study will allow sensitive differentiation between products. PD studies must be carried out with two doses of the Reference product, such that one of the doses must be superior to the other in PD response. It is suggested that the protocol for conducting this type of study should be submitted to Anvisa for prior evaluation. Two products will be considered as therapeutic equivalents if the criteria in Table II are met.

In cases where Test product does not exhibit the similarity requirements described above, the drug cannot be registered as generic or similar drug and shall follow the requirements established for innovator products, which will require full clinical trials for demonstration of efficacy and safety [52].

\section{Anvisa's Current Challenges in Defining a Guidance}

The Technical Note [51], although helpful in laying out the current agency's thinking, is still incomplete. For example, it does not include considerations about all the possible devices for OIDPs (e.g., nebulizers) and does not consider divergences in statistical approaches and in acceptance criteria for both in vitro and in vivo tests. The lack of internal and international harmonization about comparability of OIDPs is the reason for the absence of a final resolution in Anvisa. OIDPs regulation was included in the Regulatory Agenda of the agency, which means Anvisa intends to release a final guidance within the period of 2015-2016. This section discusses some of the most challenging topics, with a considerable diversity of opinion from both scientific and regulatory perspectives, which are essential for the Anvisa decision.

Aerodynamic Particle Size Distribution (APSD) Measurement and Statistical Assessement

APSD tests must be carried out with as clinically relevant settings as possible, and the same conditions should be applied for Test and Reference products for demonstration of similarity. The procedure for this analysis must be robust for active ingredient assays, repeatable for different analysts and laboratories, and be as free of bias as possible.

Table II. Acceptance Criteria for PD Studies in Brazil

Efficacy The $90 \%$ confidence interval of the PD response ratio of the Test drug relative to the Reference drug must be between 0.8 and 1.25. Other confidence interval limits previously established in protocol can be accepted through scientific justifications.

Safety There must be no evidence that the Test product is worse than the Reference product with regard to changes in vital signs, biochemical parameters and frequency of adverse events. 
A Cascade Impactor (CI) is widely used for assessing APSD of OIDPs but there is some concern about lack of correlation between the behavior of the drug in a CI apparatus and in vivo. The inlet throat suggested by pharmacopeias may not represent properly the oropharingeal deposition due to respiratory tract anatomy and humidity in physiological conditions [53]. Also, unlike in a clinical situation, the flow rate applied during a CI test for inducing particle movement is constant and, for some products, may affect the device performance [54].

Furthermore, there is no harmonization about the statistical criteria to demonstrate similarity between products. The Product Quality Research Institute (PQRI) started the first attempt to provide to regulatory agencies an analysis of methodology for data evaluation, and this resulted in the development of a combined procedure based on calculations of the chi-square ratio statistic plus impactor-sized mass-population bioequivalence (ISM-PBE) assessment, but no recommendation was defined because of limitations in discriminating ability of this method [55]. Average bioequivalence approach could be accepted, depending on the data provided by the test. A more recent proposal, which utilizes a modified chi-square ratio statistic, intends to be more robust and presented some results that could provide information about APSD equivalence but it still needs more research on its applicability [56].

Although Anvisa suggests the application of PBE for assessment of similarity, there are concerns about its suitability for APSD evaluation. Anvisa resolution about statistical approach must also take into consideration the diversity of data types for different OIDPs.

\section{Dissolution}

For OIDPs formulated as suspensions or powders, dissolution rate is an important physicochemical characteristic of particles affecting the availability of the active ingredient at the site of action. As mucocilliary clearance may cause removal of particles from the respiratory tract, it may be assumed that when Reference and Test products differ in dissolution rate, the degree of drug removed from the lung will differ.

Measuring dissolution rate for inhaled particles is not simple. For micron-sized particles, a dissolution apparatus presents significant technical problems. For hydrophobic drugs, wetting of particles may be a problem. Additionaly, due to the density of particles, floating or sedimentation may present a mixing problem [57]. There is no pharmacopeial apparatus available that eliminates all the bias of dissolution tests for OIDPs. USP, which was the first organization to discuss this subject, concluded that there was no urgency in developing or including a compendial method [58] for such a test.

For resolving these problems, some dissolution media were proposed which are more physiologically relevant, such as simulated lung fluid, composed of aqueous solutions of dipalmitoylphosphatidylcholine [59]. Also, dissolution techniques utilizing Transwell ${ }^{\circledR}$ membranes as apparatus resolve particle floating problems and mimic small volume surfaces at the site of lung deposition [60].

Dissolution testing for $\mathrm{BE}$ evaluation must have sufficient sensitivity to differentiate among orally inhaled formulations and must comply with acceptance criteria for each active ingredient in order to be able to be used as a tool for providing information relevant for in vivo behavior. No decision has been taken by Anvisa related to the need of such tests for OIDPs' registration.

\section{Pharmacokinetics}

In the past decade, the use of PK alone without the use of clinical /biomarker studies for the in vivo $\mathrm{BE}$ assessment for OIDPs has been discussed. The reluctance to accept PK alone is based on the argument that plasma concentrations of inhaled drug may not reflect the availability at the site of action and, consequently, efficacy of the product, because blood is sampled downstream from the lung.

PQRI organized in 2009 an international workshop about bioequivalence of inhaled drugs [55], in which three key questions were noted with respect to PK:

1. Are PK studies correlated to the amount of drug available in the lung?

2. Are PK studies correlated to the region of deposition of the drug in lung (central/peripheral)?

3. Are PK studies correlated to the amount of time that the drug stays in the lung?

Simulations that assessed the pulmonary fate of lipophilic steroids and their variability in the model allowed evaluation of whether the factors that determine drug efficacy in lung (including dissolution rate, central versus peripheral deposition, mucociliary clearance and others) also affects PK plasma parameters. Results suggested that the PK parameter AUC is adequate to detect differences in pulmonary deposition for drugs with negligible oral bioavailability (BA) [61].

Trial simulations and evidence from the literature suggest that PK approaches could be suitable for providing important information on the pulmonary fate of inhaled drugs. PK studies using sensitive analytical techniques are able to generate "high resolution" information on the pulmonary available dose (AUC), and residence time in the lung $\left(\mathrm{C}_{\max }\right)$ for OIDPs.

In a second PQRI workshop in 2010, further discussions about PK's role in establishing BE for OIDPs reinforced previous conclusions about $\mathrm{PK}$ as being more discriminative than PD or clinical studies, especially for inhaled corticosteroids, which lack a reproducible and sensible biological marker to demonstrate BE [62].

Inhaled drug concentrations in plasma are the result of both pulmonary and gastrointestinal (GI) absorption, because of the deposition pattern and mucociliary activity; but for drugs that show negligible oral bioavailability (BA), such as fluticasone or mometasone, plasma concentrations could be viewed as originating only from pulmonary absorption. For drugs with substantial oral BA, PK studies describe total absorption (pulmonary + GI) and, under these conditions, PK reflects potential differences in the systemic safety of a drug product. To learn about the pulmonary fate of products with non-negligible oral BA, GI absorption must be suppressed so that only pulmonary absorption would contribute to plasma concentrations of the drug. Blockage by charcoal appears to be the most feasible way to achieve this goal. 
Other methodologies for assessing the pulmonary deposition have been proposed, such as imaging studies based on gamma scintigraphy, single photon emission computed tomography and positron emission tomography (PET). However, these techniques require radiolabeling of the drug, which may alter the representativeness of commercial product and may not demonstrate adequately its deposition profile [53].

For BE demonstration, two products must present the same in vivo behavior and, from a PK perspective, it must be statistically proven that the amount of drug, the local deposition pattern and the amount of time the drug remains in the lung are not different between the Test and Reference products. Under these circumstances, PK parameters can provide as much or more valuable information for regulatory decision than PD studies.

\section{Pharmacodynamic (PD) and Clinical Studies}

In vivo $\mathrm{BE}$ demonstration may be achieved by studies that compare biological endpoints related to efficacy of the active ingredient. PD studies measure biomarkers that may be related to clinical efficacy. These studies may be conducted in healthy subjects or patients and involve quantification and comparison of physiological changes arising from the drug administration.

Both PD and clinical studies have limitations regarding sensitivity to differentiate products. This might be due to: (a) the fact that the dose may be in the upper part of the dose-response curve; and/or (b) high variability of the biomarker itself. For BE purposes, Anvisa recommends that the dose administered to subjects must be in the steep part of the dose-response curve, otherwise no difference can be observed between products. For OIDPs, this is the most critical aspect, and different clinical endpoints were proposed for inhaled drugs.

Bronchoprotection and bronchodilation evaluations are proposed models for comparison of inhaled drugs. Bronchoprotection studies should be performed in asthmatic patients and should prove same capacity for maintenance of airflow after bronchocontrictor induction with substances (e.g., metacholine) or exercise. Bronchodilatation consists of measuring the capacity of drugs to cause dilatation after induced bronchoconstriction stimulation.

Spirometry appears to show some good results for the establishment of dose-response relationship for short acting beta agonists (SABA) and long acting beta agonists (LABA) [63]. Some of the limitations of this model are the reproducibility of bronchoconstriction induction and the high variability of results obtained [64]. Also, there are some concerns about differences in establishing dose-response curves when comparing cumulative and noncumulative administration of drugs, since the former may cause a steeper dose-response curve without a clear plateau response [65].

For inhaled corticosteroids (ICS), identifying adequate biomarkers for PD evaluation is controversial. Some possibilities presented to date include sputum eosinophilia, exhaled nitric oxide (eNO) and bronchoconstriction challenges [66]. All of these are clinically relevant, but each has drawbacks. For sputum eosinophilia, variability seems to be the main limitation [67], despite demonstration of dose-response relationship on clinically relevant doses [68]. Also, enough sputum must be produced in order be analyzed, and this may not be feasible for all patients. For exhaled NO, it seems that responses at the top plateau level are already obtained following relatively low inhaled corticosteroid doses, which do not represent available marketed products [69]. An asthma stability model was also proposed for inhaled corticosteroids. Home spirometry has been demonstrated to have great power of efficacy assessment, and dose-response correlation could be shown in therapeutic dose ranges [70]. Studies are under way for additional molecules, with results still pending, which may establish PD outcomes with good statistical power for comparability.

\section{CHINA'S PERSPECTIVE (BY YING LI, SARAH LU, AND SHUGUANG HOU)}

\section{Regulatory Framework for Generic Drug Registration in China}

China Food and Drug Administration (CFDA) is the central authority for regulation and approval of drugs marketed in China. CFDA, previously named as SFDA (State Food and Drug Administration), is a ministerial-level agency directly under the State Council. It consists of 19 departments and bureaus, and 18 affiliates, some of which are directly related to drug regulation and approval processes, including Center for Drug Evaluation (CDE), National Institute for Food and Drug Control (NIFDC), Center for Certification of Drugs (CCD), Chinese Pharmacopoeia Commission (CPC) and Center for Medical Device Evaluation (CMDE) [71].

The "Provisions for Drug Registration" (PDR), issued by CFDA in 2007, defines the regulatory framework for drug registration in China [72]. A revised draft PDR [73], which was published in March 2014 for public comment, reflects CFDA recent restructuring and proposes significant amendments. Respiratory product applications follow the same registration process, regulatory requirements, and review and approval timeline as any other chemical products, as illustrated in detail on the CFDA website [74]. In some cases, the inhalation devices are required to be registered separately, following the medical device application process [75].

Generic drug applications must adhere to the 'Principles and Technical Guidelines for the Research of Chemicals with Existing National Standards' issued by CFDA in 2006 [76]. CFDA/CDE also released or published several guidelines and articles specifically for orally inhaled products, such as the Technical Guideline for Research on Quality Control of Inhalation Products in 2007 [77], the Technical Requirements for Inhaled Drug Research in 2009 [78], Clinical Trial Considerations for Inhaled Drugs for Asthma and COPD in 2009 [79], and the Technical Requirements for the Study of Changing Propellant for Marketed Inhaled Aerosols in 2011 [80]. However, the guidance for developing generic orally inhaled drugs has not yet been clearly defined by CFDA. Thus, companies must work closely with CFDA/CDE to define the strategy and requirements for their specific applications.

\section{Drug Application Processes and Timelines in China}

The CFDA classifies chemical drugs entering Chinese market from other countries into six categories as illustrated in Table III [79]. Some generic drugs already marketed outside China are 
Table III. Registration Category for Chemical Drugs Imported into China [79]

\begin{tabular}{|c|c|c|}
\hline Category & Category definition & \\
\hline I & $\begin{array}{l}\text { Drug not yet marketed either } \\
\text { in Country of Origina or } \\
\text { in China }\end{array}$ & $\begin{array}{l}\text { i. Drug substance and its preparations made by synthesis or semi-synthesis. } \\
\text { ii. New chemical monomer and its preparation extracted from natural material } \\
\text { or by fermentation. } \\
\text { iii. Optical isomers in known drugs and their preparations obtained by chiral separation } \\
\text { or synthesis. } \\
\text { iv. A fewer-component drug prepared from a multi-component drug already marketed } \\
\text { in China. } \\
\text { v. New compound preparation. } \\
\text { vi. A preparation already marketed in China but with a newly added indication not } \\
\text { yet approved in any country. }\end{array}$ \\
\hline II & Drug preparation with changed admin & stration route that is not marketed in either Country of Origin or in China \\
\hline III & $\begin{array}{l}\text { Drug marketed in Country of Origin } \\
\text { but not in China }\end{array}$ & $\begin{array}{l}\text { i. Drug substance and its preparations marketed outside of China, and/or with } \\
\text { changed formulation but no change of administration route. } \\
\text { ii. Compound preparations and/or with changed formulation, but no change } \\
\text { of administration route. } \\
\text { iii. Preparations with changed administration route compared to those } \\
\text { marketed outside China. } \\
\text { iv. A preparation already marketed in China but with a newly added } \\
\text { indication approved outside China. }\end{array}$ \\
\hline IV & \multicolumn{2}{|c|}{$\begin{array}{l}\text { Drug substance and its preparation with changed acid or alkaline radicals (or metallic elements), but without any pharmacological } \\
\text { change, where the original drug entity is already approved in China. }\end{array}$} \\
\hline $\mathrm{V}$ & \multicolumn{2}{|c|}{$\begin{array}{l}\text { Drug preparation with changed formulation but no change of administration route, where the original preparation is already } \\
\text { approved in China. }\end{array}$} \\
\hline VI & \multicolumn{2}{|c|}{ Drug substance or preparation following China's national standard. } \\
\hline
\end{tabular}

treated as new drugs (Category III), while others are considered Category VI drugs if there is a national standard in China already. Monographs in the Chinese pharmacopoeia, standards issued by CFDA, and approved specifications (albeit not published) are considered national standards.

There are two major approaches for a multi-national company to register a new or generic drug in China [80], as illustrated in Fig. 4. For a drug already marketed outside of China, a clinical trial authorization (CTA) could be obtained from CFDA, and clinical "registration" trial should then be conducted (e.g., a PK study with Chinese patients). Waiver of clinical trials may be granted in some cases, e.g., if there is an urgent clinical need. An alternative approach is for a company to include Chinese patients in their global development process for an NDA or ANDA, and conduct a separate statistical analysis on the Chinese subjects.

For a local Chinese company, a generic drug application process is illustrated in Fig. 5. Based on the 2007 Provisions for Drug Registration [72], China's regulations require that applicants own a commercial GMP facility capable of manufacturing the generic drug product. Furthermore, three batches of drug product need to be manufactured under the supervision of the local (provincial) FDA, each passing official lab testing procedures, before CDE initiates review of the drug dossier. In the revised draft PDR [73], these requirements are postponed to the time after CDE completes the review and issues the clinical trial approval. Such a revision significantly reduces the initial investment and risk for the applicants.

There is a significant backlog of reviews by CDE in China, leading to surprisingly long review waiting periods. As shown in Figs. 4 and 5, generic drug approval timelines in China may exceed six years. A "fast track" mechanism has been proposed by CFDA [81] to expedite the generic drugs of significant clinical value. However, the benefits of this process have yet to be seen for inhaled drug products in China.

\section{Bioequivalence Requirements in China}

In 2008, CFDA organized a meeting with experts and scholars (both domestic and foreign) spanning disciplines such as medicine, pharmaceutics, pharmacology and toxicology. The resulting in-depth discussion and information exchange prompted CDE to publish two articles in 2009, providing for the first time the detailed technical requirements for inhaled formulations (the main focus was on CFC to HFA propellant switch) [78] and clinical aspects of technical requirements [79] for development of generic orally inhaled drugs for the treatment of asthma and/or chronic obstructive pulmonary disease (COPD). The requirements were based on the then draft guidance from the EMEA and the experience the agency had with inhaled drug development and clinical studies. The requirements apply to both imported and domestically developed generic drugs. The CDE articles outline general principles but provide limited details of the specific requirements.

The CFDA/CDE bioequivalence requirements include measurements of both pulmonary deposition and systemic drug exposure through a variety of pharmacokinetics (PK), pharmacodynamics (PD) and/or clinical trials (CT). Specifically, two scenarios were discussed in the article [79], as summarized below:

(A) Generic drugs with a reference product approved in China (Category VI drugs)

If the original import product is available, companies should choose the original import drug product as the reference product. 


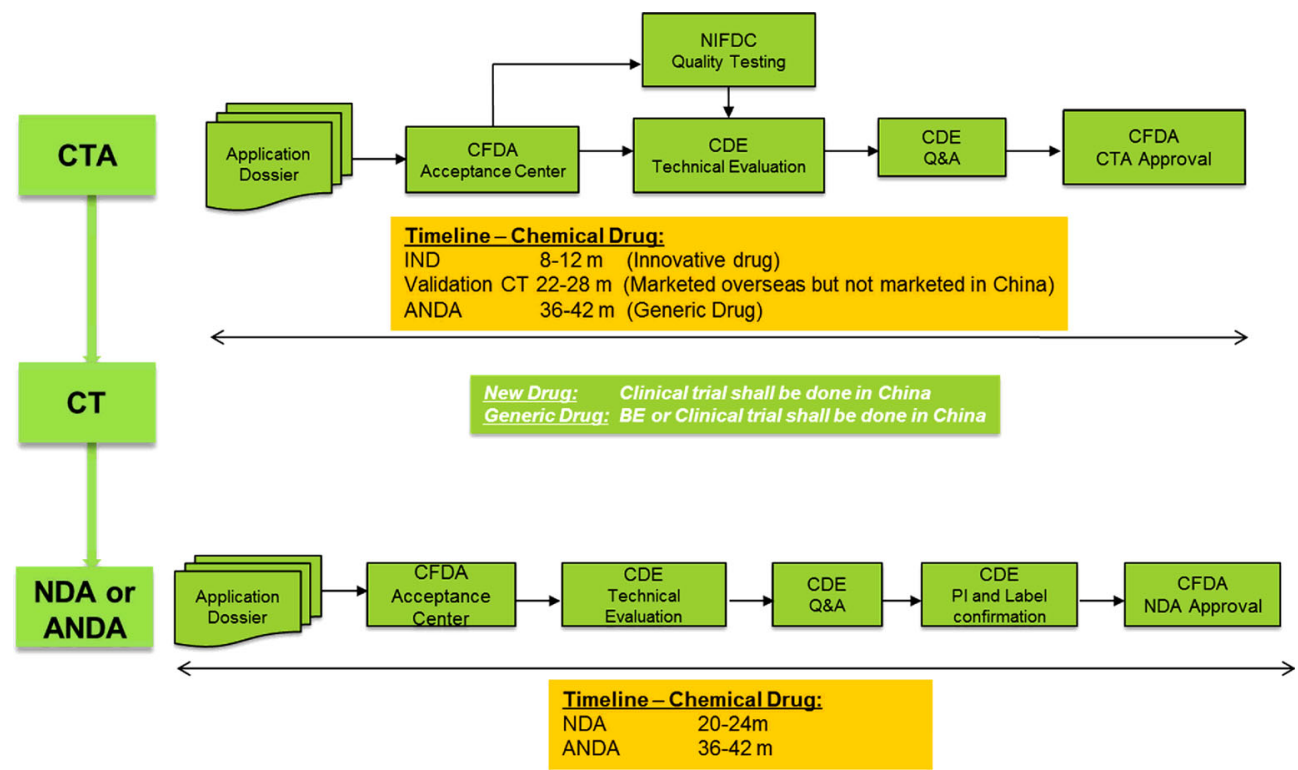

Fig. 4. Registration process for drugs imported into China, and associated timelines based on the 2013 Technical Review Report by CDE [98]

\section{Step 1 In Vitro Study}

In principle, an in vitro approach may be sufficient to demonstrate therapeutic equivalence in some cases, and the applicant may then apply for a biowaiver. There is no specific explanation of the criteria for in vitro equivalence other than mentioning that aerodynamic particle size distribution (APSD) and dose uniformity are important parameters [78]. To date, there are no cases in which the agency has granted biowaivers based on in vitro study data.

\section{Step 2 In Vivo Studies}

If in vitro comparative data cannot be considered sufficient to prove the equivalence between the study and reference products in terms of safety and efficacy, in vivo studies following one of the following two paths must be conducted. According to informal advice received by some of the authors, in case of two product strengths, testing only at the highest strength would be sufficient and equivalence could be claimed for the lower strength based on in vitro dose proportionality. There is no formal guidance, however, on this issue.

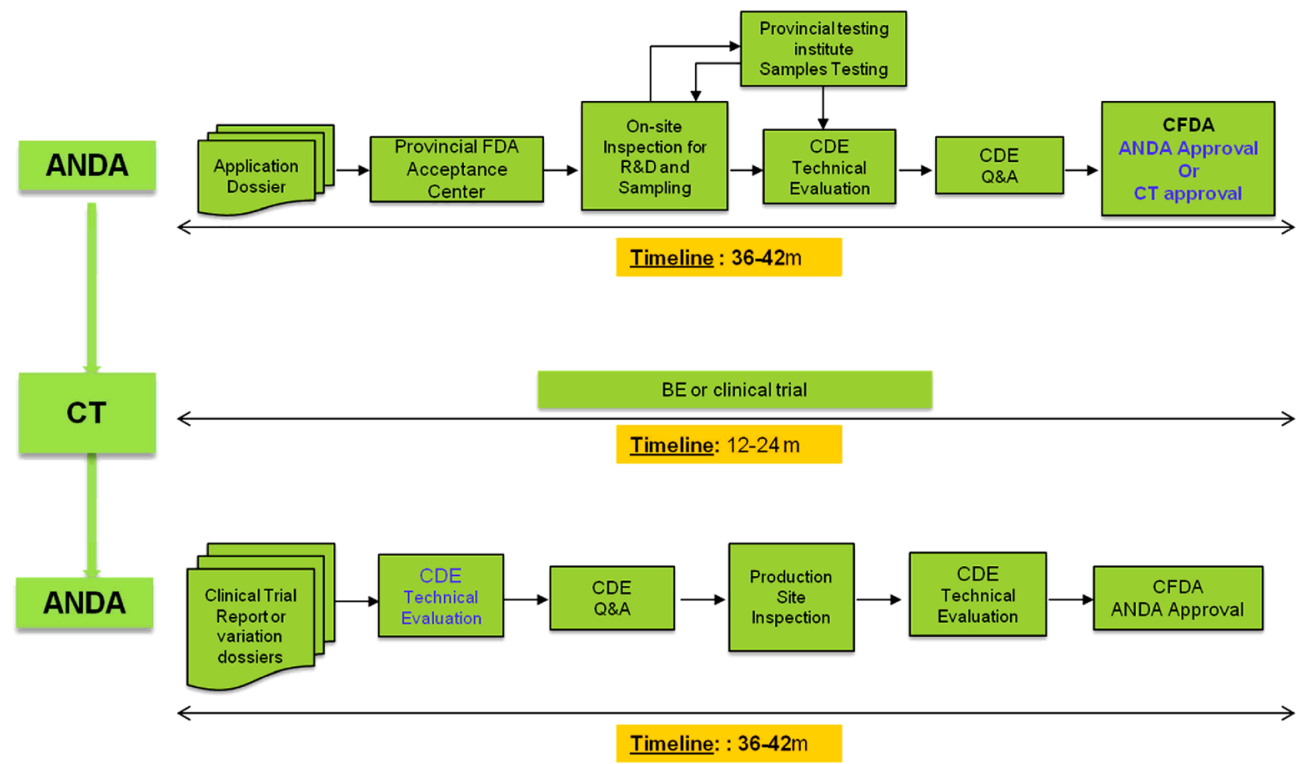

Fig. 5. Local generic drug registration process and timeline. The process illustrated in this figure is based on current PDR and the timeline is based on the technical review report of 2013 of CDE [81] 


\section{Method One: PK only}

The efficacy profile can be assumed to be equivalent if the lung deposition is concluded to be equivalent. Single-dose imaging studies or single-dose PK studies (such as active charcoal blockage) can be performed to prove similar pulmonary deposition between two formulations. PK studies to show similar systemic exposure are also required to show safety equivalence. No recommendations are currently available regarding the use of patients vs healthy subjects in PK studies, or the minimum sample size to be included in the PK studies.

\section{Method Two: PD + PK or Clinical End-Point Equivalence Between Formulations}

PD studies are required if PK endpoints cannot be used as surrogates for the demonstration of efficacy and safety of a particular pharmaceutical product.

- For bronchodilators (including short-acting $\beta 2$-adrenergic receptor agonist SABAs, long-acting $\beta 2$-adrenergic receptor agonists LABAs, and anticholinergics), single dose bronchodilation and the bronchoprovocation test (PD studies) may be used to evaluate efficacy equivalence; while single dose PK studies need to be performed to show similar systemic exposure between the formulations.

- For inhaled corticosteroids (ICS), it is recommended that a randomized, double-blind, positive controlled clinical trial be performed to demonstrate non-inferiority compared to the reference drug. No recommendations are available for efficacy endpoints. The amount of hormones (such as 24-hour urinary cortisol) is also monitored during the clinical trial to demonstrate that the impact of test drug on the HPA (hypothalamic-pituitary-adrenal) axis is not greater than that of the reference drug. In the case of fixed combinations of known active ingredients, the therapeutic equivalence of each of the active ingredients needs to be demonstrated.

If the generic drug product is seeking both asthma and COPD indications, as long as the asthma indication is proved to be equivalent, the COPD indication can be granted simultaneously as well. There are no specific recommendations for the pediatric approval.

(B) Generic drugs with reference product approved in other countries but not in China (Category III drugs)

If a formulation represents the first instance of a drug substance entry into China, the drug would be classified as a New Drug (Category III) and would have to follow the new drug application process. For a Class III product, it is impossible to run comparison tests with the innovator product because it is not marketed in China. Clinical trials that comply with the relevant international technical requirements should be carried out to prove the drug's safety and efficacy. The clinical trial results should only support the selected populations, and cannot be extended to other populations. In most cases, regulations require clinical trials to be conducted in China with at least 100 patients per arm. Due to shortage of facilities and experience with PK and PD studies in China, especially for inhalation and nasal drugs, this route is rarely used by companies, and regulators therefore have limited experience and limited guidance.

\section{INDIAN PERSPECTIVE (BY JULIET REBELLO, ABHIJIT VAIDYA, JAIDEEP GOGTAY, SHRINIVAS PURANDARE)}

\section{Regulatory System in India}

The main legislation governing drug registrations, import, manufacture, distribution and sale in India is contained in the Drugs and Cosmetic Act of 1940 [82] and Drugs and Cosmetic Rules of 1945 [83], whose origin dates back to days of the British Rule in India and a so-called "Gigantic Quinine Fraud" [84, 85]. This body of legislation also established the Central Drugs Standard Control Organization (CDSCO), and the office of its controller, the Drug Controller General of India (DCGI). The CDSCO has six zonal, four sub-zonal and eleven port/airport offices, and six laboratories to carry out its activities [86].

There are no specific guidelines issued by DCGI to assess the efficacy and safety of orally inhaled products. Generic drug applications must adhere to the "Guidelines for bioavailability and bioequivalence studies" issued by the CDSCO [87]. All trials in India are regulated by guidelines/rules such as Rule $122 \mathrm{~A}$ to $\mathrm{E}$ of Drugs and Cosmetic Act [83], Schedules Y of Drugs and Cosmetic Act and Rules thereunder (Amended in 2005) [88], Good Clinical Practice (GCP) guidelines issued by CDSCO [89], and Ethical guidelines for Biomedical Research on Human Subjects[90]. The following categories are relevant when determining the regulatory path for registering a second-entry orally inhaled product in India.

(A) The reference drug is not approved in India

If the reference product has not been approved in India, the second entry orally inhaled product would be considered as the first market entry of the drug substance and would therefore be classified as a new drug. Other situations that are classified by the Drugs and Cosmetics Act as a new drug are as follows:

- Drugs that have not been used in the country before/ drugs marketed in India for less than 4 years after receiving the marketing authorization,

- Drugs that have been approved by the DCGI but are now intended to be marketed for different indications, and

- Fixed dose combinations of two or more drugs that have been individually approved previously and are now proposed to be combined in a fixed ratio that has not been approved.

All new drugs must undergo clinical trials to determine the drug's safety and efficacy in patients in India [89, 91]. If India is part of a global clinical trial, not more than $20 \%$ of the total recruitment can be from sites in India. These trials are necessary for both domestically manufactured and imported drugs.

For a second-entry drug or if the new drug has more than one strength [87], then the following conditions are required for approval of all strengths:

a. The qualitative composition between the strengths is essentially the same.

b. The ratio of the active ingredients and excipients among/between the strengths is essentially the same.

c. The method of manufacture is essentially the same and all strengths are manufactured by the same manufacturer. 
d. Where applicable, an appropriate study has been performed on at least one of the strengths of the formulation.

e. In case of systemic availability - pharmacokinetics has been shown to be linear over the therapeutic dose range.

(B) The reference drug is approved in India

As per the guidelines for bioavailability and bioequivalence studies [87], for orally inhaled products [non solution pharmaceutical products] which are intended to act locally in the lungs, bioequivalence based on pharmacokinetics alone is not suitable and comparative clinical trials or PD studies are required to demonstrate equivalence.

PK bioequivalence for orally inhaled drugs is not a wellestablished concept in India since the knowledge of how systemic levels correlate with lung deposition is currently an evolving science. There has been no precedence of approval of a second entry orally inhaled drug based on PK bioequivalence alone. However, with more research being done demonstrating a good correlation between $\mathrm{C}_{\max }$ and $\mathrm{AUC}_{0-\mathrm{t}}$ and lung deposition, PK bioequivalence studies are increasingly accepted worldwide as being sufficient to establish equivalence of orally inhaled products [92, 93]. The pulmonary available dose is reflected through measurement of $\mathrm{AUC}_{0-\mathrm{t}}$ and the regional deposition through the measurement of $\mathrm{C}_{\text {max }}$. Hence, with adequate justification, an assessment of "interchangeability" using "pharmacokinetic equivalence "or "PK bioequivalence" between the second entry drug and the reference product may be an alternative to clinical trials.

Bioequivalence between a second-entry drug and the reference product may be considered self-evident with no further requirement of in vivo studies when the second entry drug is an inhalation aqueous solution and contains the same active substance(s) in the same concentration and essentially the same excipients in comparable concentrations as the reference product. The device may or may not be similar to the reference product. Additional in vitro testing is required to demonstrate comparable device performance between the reference inhalation product and the second-entry drug product [87].

\section{PD and Clinical Trials in India: Process Considerations and Design Recommendations}

\section{Process Considerations}

For all pharmacodynamic or clinical studies, the study design must be approved by a highly skilled professional subject expert committee (SEC) and the technical review committee (TRC) [94, 95]. The review process is completed in two stages over 180 days. In the first stage, the clinical trial documents at the time of submission are screened and the sponsor or designee is informed regarding any discrepancy in the dossier. The dossier once accepted is sent for review to the SEC, which comprises 10 experts in pulmonary disease from recognized medical colleges and government hospitals in India. This SEC meets every quarter on a predefined day based on a calendar defined by the regulator. The sponsor/designee is required to present the protocol of the intended study to the SEC. The recommendation provided by SEC is uploaded through minutes of meeting on the CDSCO website within 2 weeks. The clinical trials that are recommended by SEC to be conducted are sent for the second stage review process to the TRC. The TRC is responsible to check the qualification of the investigator based on submitted curriculum vitae, medical registration certificate, registration status of ethics committee that is reviewing documents of the investigative site, number of trials in which the investigator is actively involved, insurance policy covering compensation for injury or death during clinical trial participation and financial agreements to ensure parity across all sites and no inducement to investigator to recruit patients in the trial [92]. Trial designs that are recommended by TRC are sent to the DCGI for issuing an approval letter for conduct of the study in Indian patients. This approval letter is valid for a period of one year and contains the names of the investigators who are authorized to participate in the study. An annual report is required to be submitted to the DCGI.

For all PD/clinical trials, the investigator can be actively involved in only 3 studies at a time, which includes both pharmaceutical sponsored and academic clinical trials [96]. Further, the investigator conducting the trial should be associated with a hospital with at least 50 beds [92]. All PD/ clinical trials must be registered on the website of the Clinical Trial Registration-India [96]. Further, as per schedule Y, only a duly registered contract research organization (CRO) can carry out clinical research activities in India, and that registration must be renewed every 5 years [97].

\section{Design Recommendations}

For the PD trial design [87], some of the recommendations are similar to those expected in other world regions (e.g., the response metric should be a pharmacological or therapeutic effect relevant to the efficacy and/or safety of the drug; the response should be measured quantitatively under double-blind conditions and be recorded using objective assessments; natural history of the condition should be considered in the design and baseline should be reproducible; a crossover or parallel study design could be used, as appropriate), but other recommendations are specific to India, such as:

- Neither the test nor the reference product should produce maximal response in the course of the study, since it may be impossible to distinguish differences between formulations given in doses that produce maximal responses. Investigation of dose-response relationship may become necessary.

- Non responders should be excluded from the study by prior screening. The criteria by which responders versus non responders are identified must be stated in the protocol.

- The conventional acceptance range as applicable to pharmacokinetic studies and bioequivalence is not appropriate for PD. Instead, the acceptance range should be defined in the protocol on a case to case basis.

If there are no meaningful PD measures, then clinical trials should be conducted.

\section{Current Challenges and Future Directions in India}

The Phase I/bioequivalence centers in India need to increase their skills and expertise for instructing patients in the correct inhalation technique and minimizing variability. There is also a 
need for more centers with necessary expertise for developing complex and sensitive analytical methods to assay the low amount of orally inhaled products typically observed in PK studies.

The $\mathrm{PD} /$ clinical trial approval timelines may be prolonged as there is no fixed duration for review of the study protocols by the SEC. From the industry perspective, it would be helpful if specific recommendations on the study design were available for different classes of OIDPs.

During the past few years, much progress has been made in policies and procedures introduced by the DCGI. However, while the requirements for demonstrating bioequivalence of affordable OIP have evolved globally over the past several years, revisions are required in the Indian regulatory requirements for approval of a second entry OIDP. The revisions should include assessment of equivalence based on in vitro data alone. Only if in vitro equivalence cannot be demonstrated, the next step would be to assess equivalence using pharmacokinetic measurements. It is well recognised that clinical efficacy endpoints are insensitive for detecting differences between two inhaled products due to the shallow dose response curves for OIDPs. Overall, in view of the above mentioned challenges, it is essential to build best practices in the near future through increasing industry-regulator communication.

\section{CONCLUSIONS}

Regulatory systems and scientific recommendations and requirements for approval of generic inhalers products have some similarities but also important differences in the five world regions discussed in this article (United States, European Union, Brazil, China and India). Much progress has been made towards establishing scientific and regulatory recommendations and requirements for demonstrating bioequivalence of orally inhaled and nasal drug products. Nevertheless, for global consistency in requirements and approval practices, further research is needed to fill scientific gaps highlighted in this article. In addition, broader exchange of information and public discussions similar to those held at the 2014 Orlando Inhalation Conference (on which this article is based), would be of value.

\section{ACKNOWLEDGMENTS}

The authors would like to thank the IPAC-RS GRRO China Subgroup for reviewing the China section of this manuscript.

\section{REFERENCES}

1. Global Initiative for Asthma (GINA). Global burden of asthma. http:// www.ginasthma.org/local/uploads/files/GINABurdenReport_1.pdf. Accessed 26 Nov 2014.

2. World Health Organization. Burden of COPD. http://www.who.int/ respiratory/copd/burden/en/. Accessed 26 Nov 2014.

3. Asthma and Allergy Foundation of America. Asthma facts and figures. https://www.aafa.org/display.cfm?sub=42\&id=8. Accessed 26 Nov 2014.

4. American Lung Association. Trends in COPD (Chronic bronchitis and emphysema): morbidity and mortality. 2013. http:// www.lung.org/finding-cures/our-research/trend-reports/copd-trendreport.pdf. Accessed 26 Nov 2014.

5. EMA. Health status indicators: Self-reported prevalence. http://ec.europa.eu/health/indicators/echi/list/ echi_26a.html\#main?KeepThis=true\&TB_iframe=true\&heigh$\mathrm{t}=650$ \&width $=920$. Accessed 26 Nov 2014 .
6. Brazil Ministry of Health. Resolution SAS/MS n 709 of 17 December 2010. http://bvsms.saude.gov.br/bvs/saudelegis/sas/ 2010/prt0709_17_12_2010.html. Accessed 18 Dec 2014.

7. Brazil Federal Government. Popular Pharmacy Program. http://bvsms.saude.gov.br/bvs/saudelegis/g m/2011/ prt0184_03_02_2011_comp.html. Accessed 18 Dec 2014.

8. Datamonitor Healthcare. COPD: Epidemiology. Asthma: Epidemiology. 2012 http://www.datamonitorhealthcare.com/. Accessed 13 Nov 2014.

9. Hou S. Regulation, policy and business considerations for OIPs in China. IPAC-RS/University of Florida Orlando Inhalation Conference. 2014. https://custom.cvent.com/7B A2EE65E8B64AEBB1 E77F19E7FD30BC/files/event/8a749091c2c741228907ca5c70b619eb/ ac6157a1928e42e3a27ca2461335691a.pdf. Accessed 18 Nov 2014.

10. Jindal SK, Aggarwal AN, Gupta D, Agarwal R, Kumar R, Kaur $\mathrm{T}$, et al. Indian study on epidemiology of asthma, respiratory symptoms and chronic bronchitis in adults (INSEARCH). Int J Tuberc Lung Dis. 2012;16(9):1270-7. doi:10.5588/ijtld.12.0005.

11. U.S. Food and Drug Administration. Bioequivalence recommendations for specific products: Draft Guidance on Fluticasone Propionate; Salmeterol Xinafoate. 2013. http://www.fda.gov/ downloads/Drugs/GuidanceComplianceRegulatoryInformation/ Guidances/UCM367643.pdf. Accessed 10 Nov 2014.

12. U.S. Food and Drug Administration. Bioequivalence Recommendations for Specific Products: Draft Guidance on Albuterol Sulfate. 2013. http://www.fda.gov/downloads/Drugs/Guidance ComplianceRegulatoryInformation/Guidances/UCM346985.pdf. Accessed 10 Nov 2014.

13. Lee S. Scientific Considerations for FDA Draft Guidance on Dry Powder Inhalers of Fluticasone Propionate and Salmeterol Xinafoate. IPAC-RS/UF Orlando Inhalation Conference: Approaches in International Regulation. 2014. https://custom.cvent.com/ 7BA2EE65E8B64AEBB1E77F19E7FD30BC/files/event/ 8 a 749091 c 2 c741228907ca 5c70b619eb/31be 11 f 36 ce 14 cf1b38b789562895040.pdf. Accessed 25 Nov 2014.

14. Lee SL, Adams WP, Li BV, Conner DP, Chowdhury BA, Yu LX. In vitro considerations to support bioequivalence of locally acting drugs in dry powder inhalers for lung diseases. AAPS J. 2009;11(3):414-23.

15. Adams WP, Lee SL, Plourde R, Lionberger RA, Bertha CM, Doub WH, et al. Effects of device and formulation on in vitro performance of dry powder inhalers. Aaps J. 2012;14(3):400-9.

16. Shur J, Lee S, Adams W, Lionberger R, Tibbatts J, Price R. Effect of device design on the in vitro performance and comparability for capsule-based dry powder inhalers. AAPS J. 2012;14(4):667-76.

17. U.S. Food and Drug Administration. Guidance for Industry: Statistical approaches to establishing Bioequivalence. 2001. http://www.fda.gov/ downloads/Drugs/GuidanceComplianceRegulatoryInformation/Guidances/ucm070244.pdf. Accessed 10 Nov 2014.

18. Creticos PS, Adams WP, Petty BG, Lewis LD, Singh GJ, Khattignavong AP, et al. A methacholine challenge doseresponse study for development of a pharmacodynamic bioequivalence methodology for albuterol metered- dose inhalers. J Allergy Clin Immunol. 2002;110(5):713-20.

19. Singh GJ, Adams WP. US regulatory and scientific considerations for approval of generic locally acting orally inhaled, and nasal drug products. In: Dalby RN, Byron PR, Peart J, Farr SJ, Suman JD, editors. RDD Europe 2005. River Grove, Illinois: Davis Healthcare; 2005.

20. Kemp JP, Bierman CW, Cocchetto DM. Dose-response study of inhaled salmeterol in asthmatic patients with 24-hour spirometry and Holter monitoring. Ann Allergy. 1993;70(4):316-22.

21. Palmqvist M, Ibsen T, Mellen A, Lotvall J. Comparison of the relative efficacy of formoterol and salmeterol in asthmatic patients. Am J Respir Crit Care Med. 1999;160(1):244-9.

22. ADVAIR ${ }^{\circledR}$ DISKUS Product Label.

23. Consolidated Directive 2001/83/EC of the European Parliament and of the Council of 6 November 2001 on the Community code relating to medicinal products for human use as amended by Directive 2002/98/EC, Directive 2004/24/EC and Directive 2004/27/EC. Official Journal of the European Union. 2004;L 136:34-57.

24. Guideline on the definition of a potential serious risk to public health in the context of Article 29(1) and (2) of Directive 2001/83/ EC. Official Journal of the European Union. 2006;C 133:5-7. 
25. Committee for Medicinal Products for Human Use. Guideline on the Investigation of Bioequivalence. London: European Medicines Agency (EMA), 2010. http://www.ema.europa.eu/docs/ en_GB/document_library/Scientific_guideline/2010/01/ WC500070039.pdf. Accessed 10 Nov 2014.

26. Chen ML, Shah V, Patnaik R, Adams W, Hussain A, Conner D, et al. Bioavailability and bioequivalence: an FDA regulatory overview. Pharm Res. 2001;18(12):1645-50.

27. Committee for Human Medicinal Products, EMA. Guideline on the requirements for clinical documentation for orally inhaled products (OIP) including the requirements for demonstration of therapeutic equivalence between two inhaled products for use in the treatment of asthma and chronic obstructive pulmonary disease (COPD) in adults and for use in the treatment of asthma in children and adolescents. 2009. http://www.ema.europa.eu/ docs/en_GB/document_library/Scientific_guideline/2009/09/ WC500003504.pdf. Accessed 10 Nov 2014.

28. Sandell D. A Real Case Comparison of Average and Population Bioequivalence for Evaluation of APSD Data. Orlando Inhalation Conference: Approaches in International Regulation. 2014. https:// custom.cvent.com/7BA2EE65E8B64AEBB1E77F19E7FD30BC/ files/event/8a749091c2c741228907ca5c70b619eb/ 17c0bdf257b8428eadae07fe26f01a5c.pdf. Accessed 25 Nov 2014.

29. MacNeish CF, Meisner D, Thibert R, Kelemen S, Vadas EB, Coates AL. A comparison of pulmonary availability between ventolin (albuterol) nebules and ventolin (albuterol) respirator solution. Chest. 1997;111(1):204-8.

30. U. S.Department of Health Human Services. Food and Drug Administration. Center for Drug Evaluation and Research (CDER). Draft Guidance for Industry. Bioavailability and Bioequivalence Studies for Nasal Aerosols and Nasal Sprays for Local Action. 2003. http://www.fda.gov/downloads/Drugs/ GuidanceComplianceRegulatoryInformation/Guidances/ ucm070111.pdf. Accessed 10 Nov 2014.

31. Garcia-Arieta A. Spanish Interpretation and Application of the OIP Guideline. ISAM/IPAC-RS Workshop on European Bioequivalence Considerations for Orally Inhaled Products for Local Action. 2010. http://ipacrs.org/assets/uploads/outputs/ Arieta.pdf. Accessed 10 Nov 2014.

32. Busse WW, Brazinsky S, Jacobson K, Stricker W, Schmitt K, Vanden BJ, et al. Efficacy response of inhaled beclomethasone dipropionate in asthma is proportional to dose and is improved by formulation with a new propellant. J Allergy Clin Immunol. 1999;104(6):1215-22.

33. Harrison LI, Soria I, Cline AC, Ekholm BP. Pharmacokinetic differences between chlorofluorocarbon and chlorofluorocarbonfree metered dose inhalers of beclomethasone dipropionate in adult asthmatics. J Pharm Pharmacol. 1999;51(11):1235-40.

34. Health Canada. Therapeutic Products Directorate. Guidance to Establish equivalence or Relative Potency of Safety and Efficacy of a Second Entry Short-Acting Beta 2 -Agonist Metered Dose Inhaler (MDI). 1999. http://www.hc-sc.gc.ca/dhp-mps/alt_formats/hpfb-dgpsa/ pdf/prodpharma/mdi_bad-eng.pdf. Accessed 10 Nov 2014.

35. Ahrens RC. Pharmacodynamic testing of generic inhaler bioequivalence: unresolved issues and potential solutions. In: Dalby RN, Byron PR, Peart J, Suman JD, editors. Respiratory Drug Delivery Europe 2007. 1. Virginia Commonwealth University, Richmond; 2007. p. 1-10.

36. Lipworth BJ, Sims EJ, Das SK, Buck H, Paterson M. Doseresponse comparison of budesonide dry powder inhalers using adenosine monophosphate bronchial challenge. Ann Allergy Asthma Immunol. 2005;94(6):675-81.

37. Clearie KL, Williamson PA, Meldrum K, Gillen M, Carlsson LG, Carlholm M, et al. Pharmacokinetic and pharmacodynamic comparison of hydrofluoroalkane and chlorofluorocarbon formulations of budesonide. Br J Clin Pharmacol. 2011;71(4):504-13.

38. Kharitonov SA, Barnes PJ. Effects of corticosteroids on noninvasive biomarkers of inflammation in asthma and chronic obstructive pulmonary disease. Proc Am Thorac Soc. 2004;1(3):191-9.

39. Kelly MM, Leigh R, Jayaram L, Goldsmith $\mathrm{CH}$, Parameswaran K, Hargreave FE. Eosinophilic bronchitis in asthma: a model for establishing dose-response and relative potency of inhaled corticosteroids. J Allergy Clin Immunol. 2006;117(5):989-94.

40. Nolte H, Pavord I, Backer V, Spector S, Shekar T, Gates D, et al. Dose-dependent anti-inflammatory effect of inhaled mometasone furoate/formoterol in subjects with asthma. Respir Med. 2013;107(5):656-64.

41. Ahrens RC, Teresi ME, Han SH, Donnell D, Vanden Burgt JA, Lux CR. Asthma stability after oral prednisone: a clinical model for comparing inhaled steroid potency. Am J Respir Crit Care Med. 2001;164(7):1138-45.

42. Ahrens RC, Hendeles L, Teresi M, Lux C, Vanden BJ, Hart KA, et al. Relative potency of beclomethasone propionate (BDP), delivered by HFA-MDI, and fluticasone propionate (FP) delivered by Diskus. Eur Respir J. 2003;22 Suppl 45:236S.

43. Garcia-Arieta A. Sensitive studies with a significant doseresponse curve for inhaled corticosteroids to investigate equivalent relative potency are feasible. $\mathrm{Br} \mathrm{J}$ Clin Pharmacol. 2011;72(5):832-3.

44. Barnes PJ, Pedersen S, Busse WW. Efficacy and safety of inhaled corticosteroids. new developments. Am J Respir Crit Care Med. 1998;157(3 Pt 2):S1-S53.

45. Pauwels RA, Lofdahl CG, Postma DS, Tattersfield AE, O'Byrne $\mathrm{P}$, Barnes PJ, et al. Effect of inhaled formoterol and budesonide on exacerbations of asthma. Formoterol and Corticosteroids Establishing Therapy (FACET) International Study Group. N Engl J Med. 1997;337(20):1405-11.

46. ICH. E10 Guideline. Choice of control group and related issues in clinical trials. 2000. http://www.ich.org/fileadmin/ Public_Web_Site/ICH_Products/Guidelines/Efficacy/E10/Step4/ E10_Guideline.pdf. Accessed 25 Nov 2014.

47. Brazilian Health Surveillance Agency. 2011. Resolution RDC n ${ }^{\circ} 37,3$ August 2011. Provides information about biowaiver and substitution of bioequivalence studies. http://portal.anvisa.gov.br/wps/wcm/con$\mathrm{nect} / 1 \mathrm{c} 626 \mathrm{~d} 0040 \mathrm{cb} 51$ e 6952 e b 51 b $0133649 \mathrm{~b} /$ rdc0037_03_08_2011.pdf?MOD=AJPERES. Accessed 18 Dec 2014.

48. Brazilian Health Surveillance Agency. 2003. Resolution RDC n ${ }^{\circ}$ 16, 2 march 2007. Provides information about generic drugs registration. http://www.anvisa.gov.br/medicamentos/registro/ legis.htm Accessed 5 Nov 2014.

49. Panamerican Heath Organization. 2005. Term of Cooperation 37 for Brazilian health surveillance system reorganization. http:// new.paho.org/bra/index.php? option $=$ com_content\&view $=$ article\&id=182\&Itemid=610 Accessed 5 Nov 2014.

50. Brazilian Health Surveillance Agency. 2009. Normative instruction $\mathrm{n}^{\circ} 12,15$ October 2009. Provides information about tests for evidence of pharmaceutical equivalence and bioavailability / bioequivalence for nasal sprays and aerosols controlled dose. http://portal.anvisa.gov.br/wps/wcm/connect/ ce $6 \mathrm{dfe} 8047458 \mathrm{eff} 9843 \mathrm{dc} 3 \mathrm{fbc} 4 \mathrm{c} 6735 / \mathrm{U}$ IN - ANVIS A 12 151009.pdf?MOD=AJPERES. Accessed 18 Dec 2014.

51. Brazilian Health Surveillance Agency. 2013. Technical Note $n^{\circ} 01 /$ 2013, 25 march 2013. Provides information about conduction of tests for evidence of pharmaceutical equivalence for nasal sprays, nasal aerosols, MDIs and DPIs. http://portal.Anvisa.gov.br/wps/ wcm/connect/8366f3004f06d94787e1c7e8d88cfc99/ $\mathrm{Nota}+\mathrm{T} \% \mathrm{C} 3 \%$ A 9 c n i c a + n \% C $2 \%$ B A . + 001 2013 Disp \% C3\% B5em+sobre+os+ensaios+e+seus+respectivos+procedimentos+para+condu $\% \mathrm{C} 3 \% \mathrm{~A} 7 \% \mathrm{C} 3 \% \mathrm{~A} 3 \mathrm{o}+\mathrm{de}+$ estudos+de+equival $\%$ C3\% AAncia+farmac\% C3\%AAutica+de+sprays+nasais $\% 2 \mathrm{C}+$ aeross $\% \mathrm{C} 3 \% \mathrm{~B} 3$ is +nasais $\% 2 \mathrm{C}+\mathrm{MDIs}+$ orais+e+DPIs+orais.pdf?MOD=AJPERES Accessed 5 Nov 2014

52. Brazilian Health Surveillance Agency. 2003. Resolution RDC n ${ }^{\circ}$ 136, 29 may 2003. Provides information about new medicines registration. http://www.anvisa.gov.br/medicamentos/registro/ legis.htm Accessed 5 Nov 2014.

53. Daley-Yates PT, Parkins DA. Establishing bioequivalence for inhaled drugs: weighting the evidence. Expert Opin Drug Deliv. 2011;8(11):1531-2.

54. Meakin BJ, Cainey J, Woodcock PM. Effect of exposure to humidity on terbutaline delivery from turbuhaler dry power inhalation devices. Eur Respir J. 1993;6(5):760-1.

55. Adams WP, Ahrens RC, Chen M-L, Christopher D, Chowdhury BA, Conner DP, et al. Demonstrating bioequivalence of locally acting orally inhaled drug products (OIPs): workshop summary report. J Aerosol Med Pulmon Drug Del. 2010;23(1):1-29. doi:10.1089/jamp.2009.0803. http://www.liebertonline.com/doi/ abs/10.1089/jamp.2009.0803 (with subscription), and http:// www.pqri.org/pdfs/DTC/Articles/JAMP_article_final_draft.pdf (free of charge). Accessed 24 Nov 2014. 
56. Weber B, Lee SL, Lionberger R, Li BV, Tsong Y, Hochhaus G. A sensitivity analysis of the modified chi-square ratio statistic for equivalence testing of aerodynamic particle size distribution. AAPS J. 2013;2(15):465-76.

57. Hickey AJ: A USP perspective on dissolution testing for aerosol drugs. Resp Drug Deliv. 2012. 169-175

58. Schumacher J, Leiner S. Critical evaluation of the revised and new USP chapters for aerosols: $<601>$ and $<5>$ [Pharm Forum 2011; 37(4)]. Inhalation magazine. February 2012. http:// www.inhalationmag.com/dynamic/inh_usp_feb2012.pdf Accessed 5 Nov 2014.

59. Son YJ, McConville JT: Development of a standardized dissolution test method for inhaled pharmaceutical formulations. Int $\mathrm{J}$ Pharm. 2009 1;382 (1-2):15-22.

60. Arora D, Shah KA, Halquist MS, Sakagami M. In vitro aqueous fluid-capacity-limited dissolution testing of respirable aerosol drug particles generated from inhaler products. Pharm Res. 2010;27(5):786-95.

61. Goyal N, Hochhaus G. Demonstrating bioequivalence using pharmacokinetics: theoretical considerations across drug classes. Resp Drug Deliv. 2010;261-272.

62. O'Connor D, Adams WP, Chen ML, Daley-Yates P, Davis J, Derendorf $\mathrm{H}$, et al. Role of pharmacokinetics in establishing bioequivalence for orally inhaled drug products: workshop summary report. J Aerosol Med Pulm Drug Deliv J Aer Med Pulmon Drug Deliv. 2011;24(3):119-35. doi:10.1089/ jamp.2011.0878.

63. Lavorini F, Geri P, Camiciottoli G, Pistolesi M, Fontana GA. Agreement between two methods for assessing bioequivalence of inhaled salbutamol. Pulm Pharmacol Ther. 2008;21(2):380-4.

64. Lipworth BJ, Sims EJ, Das SK, Morice AH, O'Connor BJ. Bronchoprotection with formoterol via dry powder and metereddose inhalers in patients with asthma. Annals Allerg Asthma Immunol. 2005;95:283-92.

65. Fishwick D, Bradshaw L, Macdonald C, Beasley R, Gash D, Bengtsson $\mathrm{T}$, et al. Cumulative and single-dose design to assess the bronchodilator effects of beta2-agonists in individuals with asthma. Am J Respir Crit Care Med. 2001;163(2):474-7.

66. Kelly HW. Comparative potency and clinical efficacy of inhaled corticosteroids. Respir Care Clin N Am. 1999;5(4):537-53.

67. van Rensen EL, Straathof KC, Veselic-Charvat MA, Zwinderman AH, Bel EH, Sterk PJ. Effect of inhaled steroids on airway hyperresponsiveness, sputum eosinophils, and exhaled nitric oxide levels in patients with asthma. Thorax. 1999;54(5):403-8.

68. Jatakanon A, Kharitonov S, Lim S, Barnes PJ. Effect of differing doses of inhaled budesonide on markers of airway inflammation in patients with mild asthma. Thorax. 1999;54(2):108-14.

69. Adams WP: Asthma stability model for inhaled corticosteroid dose-response. Topic 3: Use of inhaled corticosteroid dose response as a means to establish bioequivalence of inhalation drug products. FDA CDER Advisory Committee for Pharmaceutical Science and Clinical Pharmacology. Rockville, MD, July 23, 2008.

70. Evans C, Cipolla D, Chesworth T, Agurell E, Ahrens R, Conner D, Dissanayake S, Dolovich M, Doub W, Fuglsang A, Arieta AG, Golden M, Hermann R, Hochhaus G, Holmes S, Lafferty P, Lyapustina S, Nair P, O'Connor D, Parkins D, Peterson I, Reisner C, Sandell D, Singh GJP, Weda M, Watson P: Equivalence considerations for orally inhaled products for local action - ISAM/IPAC-RS European workshop report. J Aerosol Med Pulm Drug Deliv. 2012. 1-23.

71. CFDA's structure, [in English: http://eng.sfda.gov.cn/WS03/ CL0755/; in Chinese: http://www.sfda.gov.cn/WS01/CL0003/] Accessed 6 Nov 2014.

72. China Food and Drug Administration (2007): Provisions for drug registration http://eng.sfda.gov.cn/WS03/CL0768/61645.html Accessed 6 Nov 2014.

73. CFDA's draft version of the revised Provisions for Drug Registration国家食品药品监督管理总局《药品注册管理办法(修 改草案) 》http://www.sda.gov.cn/WS01/CL0778/96959.html Accessed 6 Nov 2014.

74. China Food and Drug Administration: Official DRUG CFDA application process http://eng.sfda.gov.cn/WS03/CL0769/ Accessed 6 Nov 2014.
75. China Food and Drug Administration: Medical device registration. http://eng.sfda.gov.cn/WS03/CL0770/ Accessed 6 Nov 2014.

76. Principles and Technical Guidelines for the Research of Chemicals with Existing National Standard (2006)

http://www.sda.gov.cn/WS01/CL1036/10613.html Accessed 6 Nov 2014.

77. China Food and Drug Administration (2007): The Technical Guideline for research on quality control of inhalation products (吸入制剂质量控制研究技术指导原则) http://www.acec.gov.cn/info/info/2009224844530.pdf Accessed 6 Nov 2014.

78. Wei N. Technical Requirements for Inhaled Drug Research, CDE, CFDA ((吸入制剂药学研究的相关技术要求, by魏农农), http://www.cde.org.cn/dzkw.do?method=largePage\&id=310929 Accessed 6 Nov 2014.

79. $\mathrm{Li}$ Requirements for the Study of Changing Propellant for Marketed Inhaled Aerosols http://www.sda.gov.cn/WS01/ CL0844/61334.html Accessed 6 Nov 2014

80. China Registration Category for Chemical Drugs http:// www.sfdachina.com/info/150-1.htm Accessed 6 Nov 2014.

80. Li Y, Nagao L, Liu M, Webb K. Addressing China's Growing Need for Inhaled Drugs: Development Strategies for Marketing, Distribution and Regulation. Respiratory Drug Delivery 2014, Volume 1. pp 131-142. Edited by Dalby, RN, Byron, PR, Peart, J, Farr, SJ, Suman, JD, Young PM. DHI Publishing; River Grove, IL: 2014.

81. CFDA's opinion on deepening the reform of drug review and approval of drugs to further encourage innovation ((国家食品药 品监督管理局关于深化药品审评审批改革进一步鼓励药物创新的 意见) http://www.sda.gov.cn/WS01/CL0844/78576.html Accessed 6 Nov 2014.

82. Government of India, Ministry of Health and Family Welfare. Drug and Cosmetics Act. 1940. http://www.medindia.net/ indian_health_act/drugs_and_cosmetics_act_1940/list-ofacts.htm. Accessed 13 Nov 2014.

83. Government of India, Ministry of Health and Family Welfare. The drugs and cosmetics act, 1940 (as amended up to the 30th June, 2005) and The Drugs and Cosmetics Rules, 1945 (as amended up to the 30th June, 2005). http://cdsco.nic.in/ writereaddata/Drugs\&CosmeticAct.pdf. Accessed 13 Nov 2014.

84. Patricia Barton. The Great Quinine Fraud: Legality Issues in the "Non-Narcotic" Drug Trade in British India. Social History of Alcohol and Drugs, Volume 22, No 1 (Fall 2007).

85. Singh H. Sir Ram nath chopra: a profile. J Young Pharm. 2009;1:192-4.

86. Central Drugs Standards Control organization. Ministry of Health and Family Welfare. http://www.cdsco.nic.in/forms/ list.aspx?lid=1368\&Id=0. Accessed 10 Nov 2014.

87. Government of India, Ministry of Health and Family Welfare. CDSCO. Guidelines for bioavailability and bioequivalence studies. 2005. http://www.drugscontrol.org/gfbbs.pdf. Accessed 13 Nov 2014.

88. Schedule Y. Drugs and Cosmetics rules, Ministry of Health and Family Welfare-Dept of Health 2005. http://dbtbiosafety.nic.in/ act/schedule_y.pdf Accessed 10 Nov 2014.

89. CDSCO., Good Clinical Practices For Clinical Research in India. 2004. http://cdsco.nic.in/html/GCP1.html. Accessed 13 Nov 2014

90. Indian council of medical research (Second Amendment), Ethical guidelines for biomedical research on human participants 2006. http://icmr.nic.in/ethical_guidelines.pdf Accessed 10 Nov 2014.

91. Draft guidance on approval of clinical trials and New drugs. Central drugs standards and control organisation. Directorate General of Health Services, Ministry of Health and Family Welfare, Govt of India. July 2011. http://www.cdsco.nic.in/ writereaddata/Guidance_for_New_Drug_Approval23.07.2011.pdf. Accessed 10 Nov 2014.

92. Garcia-Arieta A. In vitro and PK studies for generics based on European experience. 2014 Presentation at the IPAC-RS/University of Florida Orlando Inhalation Conference. https:// custom.cvent.com/7BA2EE65E8B64AEBB1E77F19E7FD30BC/ files/event/8a 749091 c2 c741228907ca5c70b619eb/ f1667a8615fe4a55ad931c409392c08e.pdf. Accessed 18 Nov 2014.

93. Mendes LSG. Considerations for generic OIPs in Brazil2014 Presentation at the IPAC-RS/University of Florida Orlando Inhalation Conference. https://custom.cvent.com/7BA2EE65E8B64A 
EBB1E77F19E7FD30BC/files/event/8a749091c2c7412 28907ca5c70b619eb/98f6e2e31b024eed9c8f81c31b3e9242.pdf. Accessed 18 Nov 2014

94. Government of India. Office order by CDSCO of 03 July 2014 "Procedure for review of applications of clinical trials and new drugs- renaming of New Drugs Advisory Committees (NDACs)". http://www.cdsco.nic.in/writereaddata/ officer\%20order\%201.pdf. Accessed 18 Nov 2014.

95. Government of India. Office order by CDSCO of 03 July 2014 "Limiting number of clinical trials an investigator can undertake at a time". http://www.cdsco.nic.in/writereaddata/officer\%20order \%202.pdf. Accessed 18 Nov 2014.

96. Tharyan P, Ghesri D. Registering clinical trials in India: a scientific and ethical imperative. Natl Med J India. 2008;21:31-4.

97. Babu G. Centre releases draft rule for schedule Y-1 mandating registration of CROs. Pharmabiz.com. 2009. http://pharmabiz.com/ NewsDetails.aspx?aid=51414\&sid=2. Accessed 18 Nov 2014.

98. CFDA CDE annual Drug Evaluation Report of $2013 \mathrm{http}: / /$ www.cde.org.cn/news.do? method=viewInfoCommon\&id=313280 Assessed 6 Nov 2014. 